\title{
BMJ Open Systematic review of clinician-directed nudges in healthcare contexts
}

\author{
Briana S Last (D) , Alison M Buttenheim, ${ }^{2,3,4}$ Carter E Timon, ${ }^{5}$ Nandita Mitra, ${ }^{6}$ \\ Rinad S Beidas $3,4,7,8,9$
}

To cite: Last BS, Buttenheim AM, Timon CE, et al. Systematic review of clinician-directed nudges in healthcare contexts. BMJ Open 2021;11:e048801. doi:10.1136/ bmjopen-2021-048801

- Prepublication history and supplemental material for this paper is available online. To view these files, please visit the journal online (http://dx. doi org/10.1136/bmjopen-2021 048801).

Received 08 January 2021 Accepted 12 May 2021

Check for updates

(c) Author(s) (or their employer(s)) 2021. Re-use permitted under CC BY-NC. No commercial re-use. See rights and permissions. Published by BMJ.

For numbered affiliations see end of article.

Correspondence to

Ms Briana S Last;

brishiri@sas.upenn.edu

\section{ABSTRACT}

Objective Nudges are interventions that alter the way options are presented, enabling individuals to more easily select the best option. Health systems and researchers have tested nudges to shape clinician decision-making with the aim of improving healthcare service delivery. We aimed to systematically study the use and effectiveness of nudges designed to improve clinicians' decisions in healthcare settings.

Design A systematic review was conducted to collect and consolidate results from studies testing nudges and to determine whether nudges directed at improving clinical decisions in healthcare settings across clinician types were effective. We systematically searched seven databases (EBSCO MegaFILE, EconLit, Embase, PsycINF0, PubMed, Scopus and Web of Science) and used a snowball sampling technique to identify peer-reviewed published studies available between 1 January 1984 and 22 April 2020. Eligible studies were critically appraised and narratively synthesised. We categorised nudges according to a taxonomy derived from the Nuffield Council on Bioethics. Included studies were appraised using the Cochrane Risk of Bias Assessment Tool.

Results We screened 3608 studies and 39 studies met our criteria. The majority of the studies $(90 \%)$ were conducted in the USA and $36 \%$ were randomised controlled trials. The most commonly studied nudge intervention (46\%) framed information for clinicians, often through peer comparison feedback. Nudges that guided clinical decisions through default options or by enabling choice were also frequently studied (31\%). Information framing, default and enabling choice nudges showed promise, whereas the effectiveness of other nudge types was mixed. Given the inclusion of non-experimental designs, only a small portion of studies were at minimal risk of bias (33\%) across all Cochrane criteria.

Conclusions Nudges that frame information, change default options or enable choice are frequently studied and show promise in improving clinical decision-making. Future work should examine how nudges compare to nonnudge interventions (eg, policy interventions) in improving healthcare.

\section{RATIONALE}

Research from economics, cognitive science and social psychology have converged on the finding that human rationality is 'bounded'. The intractability of certain decision problems, constraints on human cognition and
Strengths and limitations of this study

This systematic review synthesises the growing research applying nudges in healthcare contexts to improve clinical decision-making.

- The review uses both systematic search strategies and a snowball sampling approach, the latter of which is useful for identifying relatively novel literature.

- Meta-analysis was not possible due to heterogeneity in methods and outcomes.

- The systematic review was not designed to synthesise research wherein study authors did not identify the intervention as a nudge.

scarcity of time and resources lead individuals to employ mental shortcuts to make decisions. These mental shortcuts, often called heuristics, are strategies that overlook certain information in a problem with the goal of making decisions more quickly than more deliberative methods. ${ }^{2}$ While heuristics can often be more accurate than more complex mental strategies, they can also lead to errors and suboptimal decisions. ${ }^{2}{ }^{3}$ Researchers have discovered interventions to harness the predictable ways in which human judgement is biased to improve decisions. These interventions, known as 'nudges,' reshape the 'choice architecture,' or the way options are presented to decision-makers, to optimise choices. ${ }^{4}$ Nudges have been applied to retirement savings, organ donation, consumer health and wellness, and climate catastrophe mitigation demonstrating robust effects..$^{5-8}$

As with retirement savings and dietary choices, clinical decision-making-clinicians' process of determining the best strategy to prevent and intervene on clinical mattersis complex and error-prone. Clinicians often use heuristics when making diagnostic and treatment decisions. ${ }^{9-11}$ For example, clinicians are influenced by whether treatment outcomes are framed as losses or gains (eg, doctors prefer a riskier treatment when the outcome is framed in terms of lives lost rather 
than lives saved) ${ }^{12}$ Heuristics can lead to medical errors. ${ }^{13}$ In the face of complex medical decisions, clinicians tend to choose the default treatment option (despite clinical guidelines) or conduct clinical examinations that confirm their prior beliefs. ${ }^{1415}$

Choice architecture influences clinicians' behaviour regardless of whether clinicians are conscious of it, creating opportunities for nudges. ${ }^{16}$ Clinical decisions are increasingly made within digital environments such as electronic health record (EHR) systems. ${ }^{17}$ More than $90 \%$ of US hospitals now use an EHR. ${ }^{18}{ }^{19}$ Researchers have explored the potential to use these ubiquitous electronic support systems to shape clinical decisions through nudges. They have subtly modified the EHR choice architecture by changing the default options for opioid prescription quantities or by requiring physicians to provide free-text justifications for antibiotic prescriptions. ${ }^{16}$ Even when nudges are not implemented in the EHR, researchers extract aggregate data from the EHR, suggesting its increasing role in the study of clinical decision-making. ${ }^{20}$

As health systems and researchers have embraced nudges in recent years, there is growing interest in understanding which nudges are most effective to improve clinical decision-making. Taxonomising nudges is advantageous because many nudges explicitly target heuristics, revealing the mechanism of behaviour change. ${ }^{21}$ If nudges that leverage people's tendency to adhere to social norms are consistently more effective than nudges that harness clinicians' default bias, then future nudges can be designed with this insight. Two systematic reviews were recently conducted to evaluate the effectiveness of healthcare nudges. Though both reviews demonstrate promise for the effectiveness of nudges, they offer somewhat conflicting evidence on the most studied and most effective nudge types, suggesting that an additional review may be useful. ${ }^{22} 23$ Our review offers complementary and non-overlapping insights on the study of nudges in healthcare settings for the following reasons: (1) we do not exclusively study physicians as our target population, ${ }^{23}$ instead we include all healthcare workers; and (2) we do not restrict our research to randomised controlled trials (RCTs) reported in the Cochrane Library of systematic reviews. ${ }^{22}$

Our review also makes use of a nudge taxonomy derived from the widely cited Nuffield Council on Bioethics intervention ladder wherein interventions increase in potency and constrain choice with each new rung. ${ }^{24} 25$ Interventions on the bottom of the ladder tend to be more passive, offering decision-makers information and reminders. Interventions in the middle of the ladder leverage psychological insights to motivate decisionmakers either through social influence or by encouraging planning. At the top of the ladder, interventions are more assertive and reduce decisions to a limited set of choices or by creating default options. The nudge ladder categorises nudges by the psychological mechanisms by which they operate, the degree to which they maintain autonomy and have the additional advantage of aligning with existing public health and quality improvement literature that make use of the Nuffield Council ladder. ${ }^{46}$ The nudge ladder offers insights on the heuristics most relevant to the clinical decision-making process and can support health systems in selecting and applying nudges to improve clinical decision-making.

\section{Objective}

We systematically evaluated nudge interventions directed at clinicians in healthcare settings to determine the types of nudges that are most studied and most effective in improving clinical decision-making compared with other nudges, non-nudge interventions or usual care. All quantitative study designs were included in our review.

\section{METHODS}

\section{Protocol and registration}

Before initiating this review, we searched the international database PROSPERO to avoid duplication. After establishing that no such review was underway, we prospectively registered our review (https://www.crd.york.ac.uk/ prospero/display_record.php? RecordID=123349).

\section{Eligibility criteria}

\section{Types of participants}

We included only empirical studies published in peerreviewed journals studying nudges directed at clinicians working in healthcare settings. Clinicians were defined as workers who provide healthcare to patients in a hospital, skilled nursing facility or clinic. Examples of clinicians include physicians, nurses, medical assistants, physician assistants, clinical psychologists, clinical social workers and lay health workers. Studies that exclusively nudged patients were not included.

\section{Types of intervention}

Nudges were defined as 'any aspect of the choice architecture that alters people's behaviour in a predictable way without forbidding any options or significantly changing their economic incentives'. ${ }^{4}$ Alterations to choice architecture included changes to the information provided to the clinician (eg, translating information, displaying information, presenting social benchmarks), altering the decision structure of the provider (eg, modifying default options, changing choice-related effort, changing the number or types of options or changing decision consequences) and providing decision aids (eg, offering reminders or commitment devices). ${ }^{27}$ The study authors did not need to identify the intervention as a nudge to be considered for study inclusion, however given the systematic search string, which includes several behavioural economics terms (see online supplemental appendix 1), studies that did not self-identify as behavioural economic interventions were unlikely to be included.

Interventions that required sustained education or training were not considered nudges. No options could 


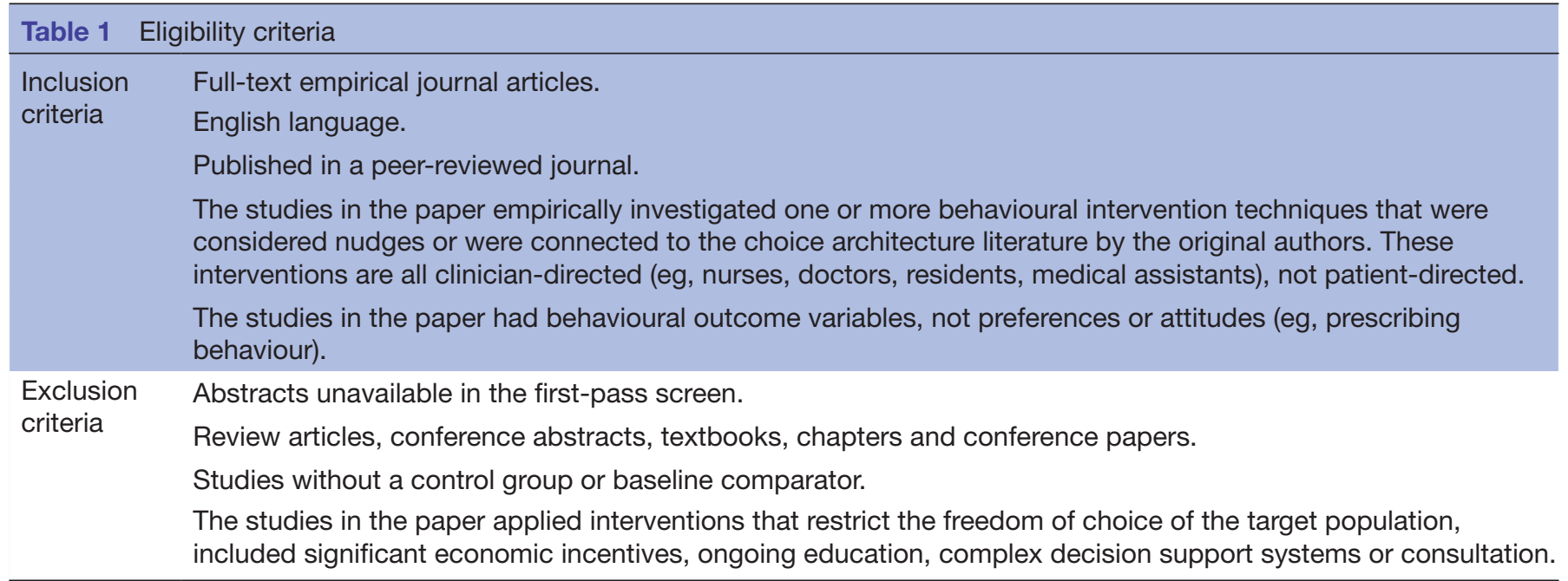

be forbidden and there could be no financial incentives. ${ }^{28}$ Though some financial incentives for clinicians may be considered nudges, most studies on financial incentives for clinicians involve significant compensation or "pay for performance' - of which there is already an existing literature. $^{29}$

Nudges guided clinicians to make improved clinical decisions, including (but not limited to) increasing the uptake of evidence-based practices (EBPs), adherence to health system or policy guidelines and reducing healthcare service costs. EBPs refer to clinical techniques and interventions that integrate the best available research evidence, clinical expertise and patient preferences and characteristics. ${ }^{30}$ Study authors had to provide the evidentiary rationale for the nudge.

We did not include studies that analysed the sustainability of nudges in the same study setting and/or sample of providers. In order to analyse studies with independent samples, we included the primary paper and not follow-up papers.

\section{Types of studies}

All study designs were included that had a control or baseline comparator-the control or baseline could be usual care or another intervention (nudge or non-nudge). For studies with parallel intervention groups, we did not require that allocation of interventions be randomised (ie, quasi-experimental studies were included). Exclusively qualitative studies were not included. See table 1 for eligibility criteria.

\section{Search}

\section{Snowball sampling}

The initial search strategy was based on a snowball sampling method ${ }^{31}$ using the references from a published commentary on the uses of nudges in healthcare contexts. ${ }^{16}$ Reviews identified during the preliminary stage of the systematic search process were also used to snowball articles, though these largely resulted in duplicates. Articles were reviewed at the title level to immediately identify those to be excluded. Those tentatively included were reviewed at the abstract level, followed by the full text for those meeting criteria. Following completion of screening of records retrieved via snowball, a systematic search of several databases was completed.

The methodology for the search was designed based on standards for systematic reviews, ${ }^{32}$ in consultation with a medical librarian, as well as with two experts from the field of healthcare behavioural economics. The databases used were: EconLit, Embase, EBSCO MegaFILE, PsycINFO, PubMed, Scopus and Web of Science.

Search terms included combinations, plurals and various conjugations of the words relating to identified nudge interventions. The search string and strategy from $^{6}$ was used as a basis for search terms, but adjusted to reflect our research question (see table 1). All peerreviewed empirical studies published prior to the completion of our search phase (ie, April 2020) were eligible for this review. See online supplemental appendix 1 for the search strings.

\section{Data collection process}

Following retrieval of all records, duplicates were removed using Zotero (www.zotero.org) and via manual inspection. Article screening involved two stages. First, all records were screened at the title and abstract level by a team of four coders (BSL, CT and two research assistants) using the web-based application for systematic reviews, Rayyan (https://rayyan.qcri.org). Criteria in this first-pass screening were inclusive-that is, all interventions directed at clinicians were included. To establish reliability, the coders screened the same 20 articles and then reviewed their screening decisions together. Any disagreements were resolved by consensus. This process was repeated three additional times until 80 articles were screened by all four coders and sufficient reliability was established. Reliability was excellent (Fleiss' $\kappa=0.96$ ). For the remainder of the screening process, screening was done independently by all four coders; the team met weekly to discuss edge cases. This screening process was followed by a full-text examination to determine eligibility 
according to more stringent inclusion and exclusion criteria (see table 1). This screening process was done as a team and determinations of article inclusion were decided by consensus.

\section{Patient and public involvement}

Patients and the public were not involved in the design, conduct or reporting of this research.

\section{Data items}

Study characteristics and outcomes were extracted and tabulated systematically per recommendations for systematic reviews. ${ }^{32}$ These data included: (1) study characteristics-author names, healthcare setting, study design, country, date of publication, details of the intervention, justification for the nudge, sample size, primary outcomes, main findings and whether the effect was statistically significant; (2) nudge type; and (3) risk of bias assessment.

BSL and RSB trained the coding team (four Master's students in a Behavioural and Decision Sciences programme) in data extraction. The team coded articles $(n=16)$ together to ensure consensus. RSB reviewed a random sample $(n=5)$ of the final articles to ensure reliability with systematic review reporting standards. BSL subsequently coded the remaining articles $(n=18)$.

\section{Outcomes}

We only included studies that included objective measures of clinician behaviour in real healthcare contexts. Studies that measured clinicians' choices in vignette or simulation studies were not included. Results could be presented as either continuous (eg, number of opioid pills prescribed) or binary (eg, whether physicians ordered influenza vaccinations). Outcomes were measured either directly (eg, antibiotic prescribing rates) or indirectly (eg, using cost to estimate changes in antibiotic prescriptions). Participants could not report on their own behaviour because clinicians' self-report can be inaccurate. ${ }^{33}$ Both absolute measurements and change relative to baseline were accepted.

\section{Risk of bias in individual studies}

We evaluated whether the studies included in the systematic review were at risk for bias, using the Cochrane Risk of Bias Tool. ${ }^{32}{ }^{34}$ BSL trained CT and they assessed articles $(n=2)$ together to ensure consensus. CT independently coded $(n=12)$ articles and BSL coded the remaining articles $(n=27)$. The team met weekly to discuss articles that they were uncertain about and resolved discrepancies by consensus.

\section{Data synthesis}

In order to examine which types of nudges were most studied and most effective, we calculated the number

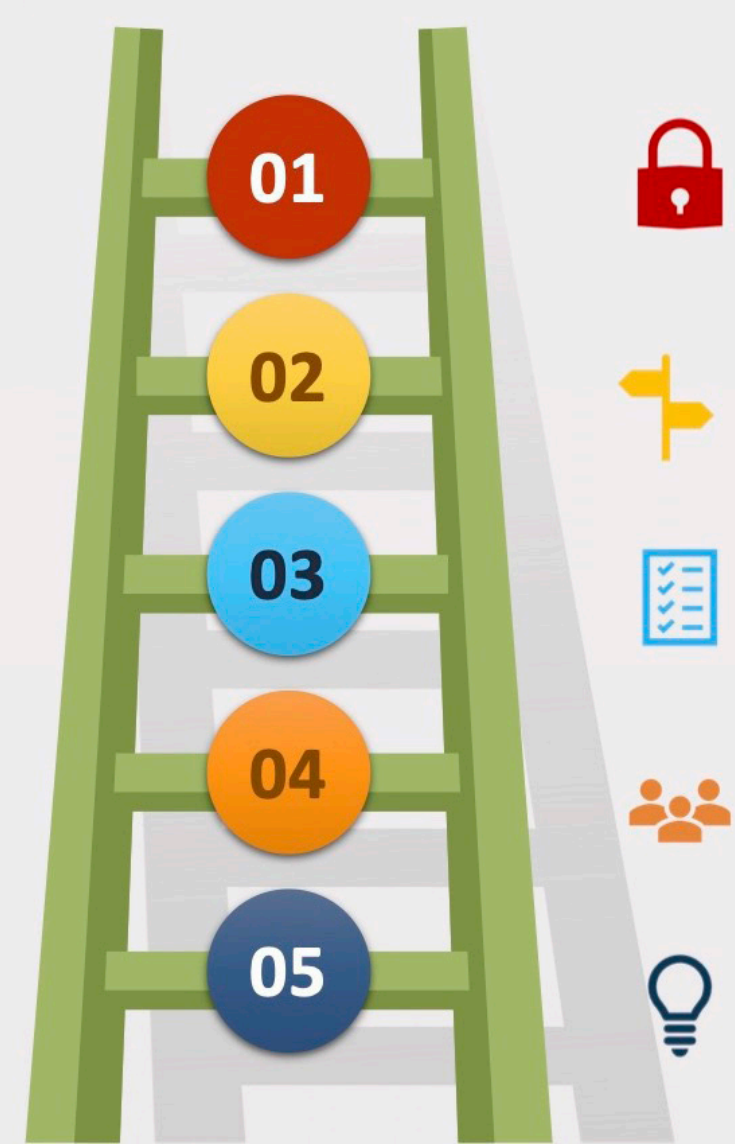

\section{Guide Choice Through Defaults}

Nudges include: creating automated laboratory orders; reducing standard opioid prescriptions to smaller doses; making the generic medication the default

\section{Enable Choice}

Nudges include: reducing effort by putting a seat in the ED for clinicians to spend more time with patients; increasing effort to prescribe brand name medication; presenting choices in the electronic health record

\section{Prompt Implementation Commitments}

Nudges include: prompting individuals to think through their concrete plan for how they will implement the intervention; ask individuals to precommit to an action

\section{Frame Information}

Nudges include: social comparison feedback using leaders or descriptive norm as the reference point; setting up accountable justification for actions that do not adhere to guidelines; audit and feedback

\section{Provide Information}

Nudges include: regular emails about the clinical guidelines, text message reminders about evidence-based practices; posters around the office; best practice advisory alerts in the electronic health record.

Figure 1 Ladder of nudge interventions. Note, ladder adapted from 24 25. ED, emergency department. 
and percentage of studies using each nudge intervention according to the nudge ladder (see figure 1). We reported the effect and statistical significance of the effect when a primary outcome was clearly identified in the study. If no primary outcome was identified by study authors, we determined a primary outcome based on the main research question. For studies that reported multicomponent nudges-ie, interventions that combine several nudges together-we reported the total effect of the intervention. For multicomponent nudge interventions, we coded them according to the nudge ladder with all of the nudge types that apply. For studies with multiple nudge treatment groups, we reported the effect of each treatment arm separately. Only nudge interventions were compared with the control arms.

Due to the differences in the exposure, behavioural outcomes and study designs interventions could not be directly compared with one another quantitively using effect sizes. ${ }^{35}$ Hence, meta-analysis of nudge effects was infeasible. To synthesise the results, we used a vote counting method based on the direction and significance of the effect for each study; caution when interpreting results based on statistical significance is warranted. ${ }^{32}$ If a simple majority of nudges were significant in a nudge category, the category was deemed effective.

\section{RESULTS}

\section{Study selection}

The systematic database search identified 3586 entries, which were combined with another 22 articles of interest identified by the snowball sampling method, totaling 3608 articles (see online supplemental appendix 1 for yield). After deduplication of records from the respective databases and snowball sampling techniques, 2486 article records remained. Of the 2486 articles, 2486 articles from the systematic search and snowball method were retrievable and screened in the first stage of title and abstract screening, which reduced the total number of full-text screens to 133 unique articles. Of the 133 articles that were full-text screened, 39 articles ${ }^{20}{ }^{36-73}$ met inclusion criteria and the data from these were extracted and evaluated in this review (see Preferred Reporting Items for Systematic Reviews and Meta-Analyses diagram in figure 2).

\section{Study characteristics}

The characteristics of the included studies are summarised in table 2 . The majority $(n=35,90 \%)$ of studies were conducted in the USA; two $(5 \%)$ were conducted in the UK, one $(3 \%)$ in Belgium and one $(3 \%)$ in Switzerland. Studies were set in a variety of healthcare contexts (eg, outpatient clinics, primary care practices, emergency
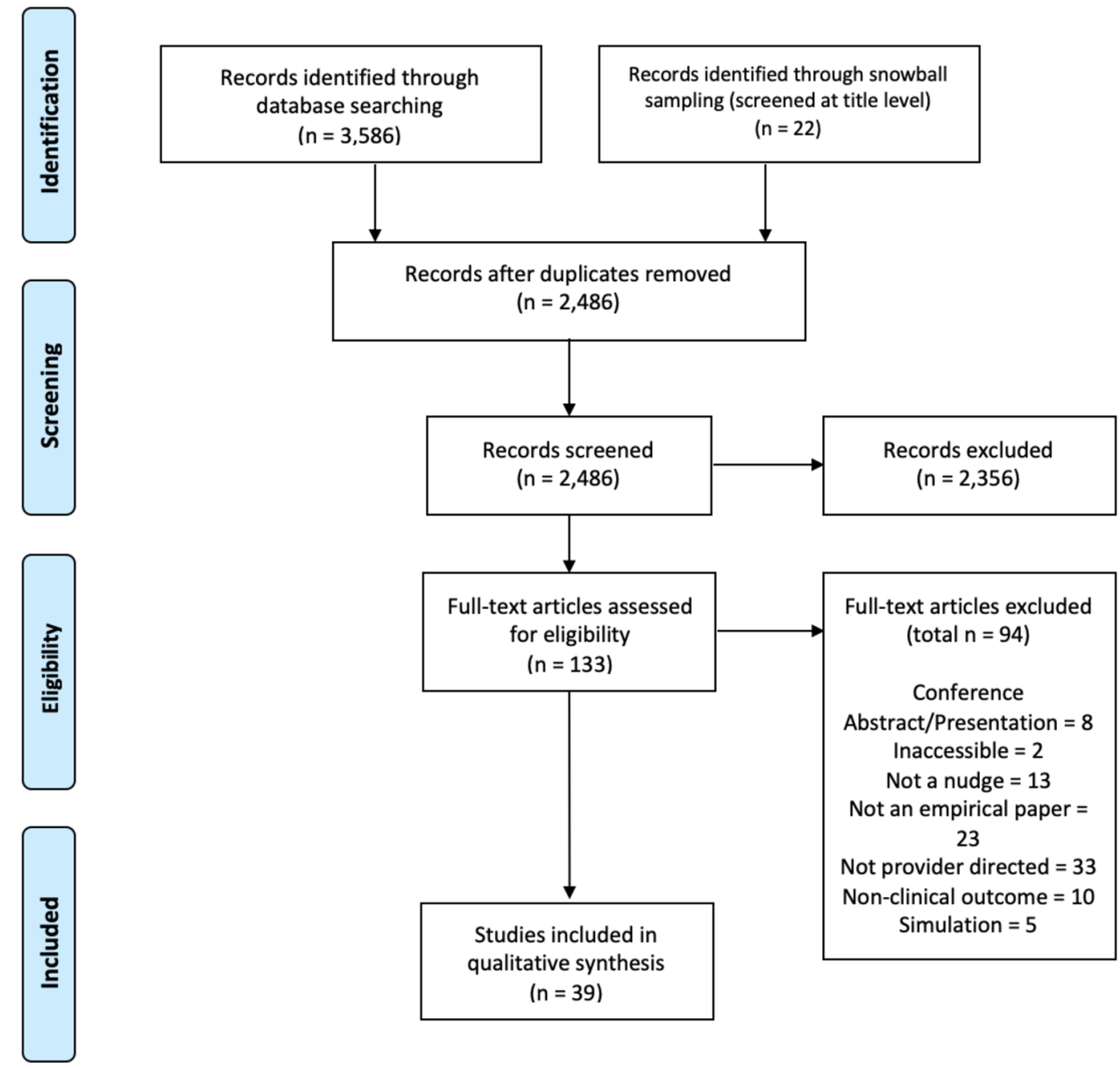

Figure 2 Preferred Reporting Items for Systematic Reviews and Meta-Analyses flow diagram. 


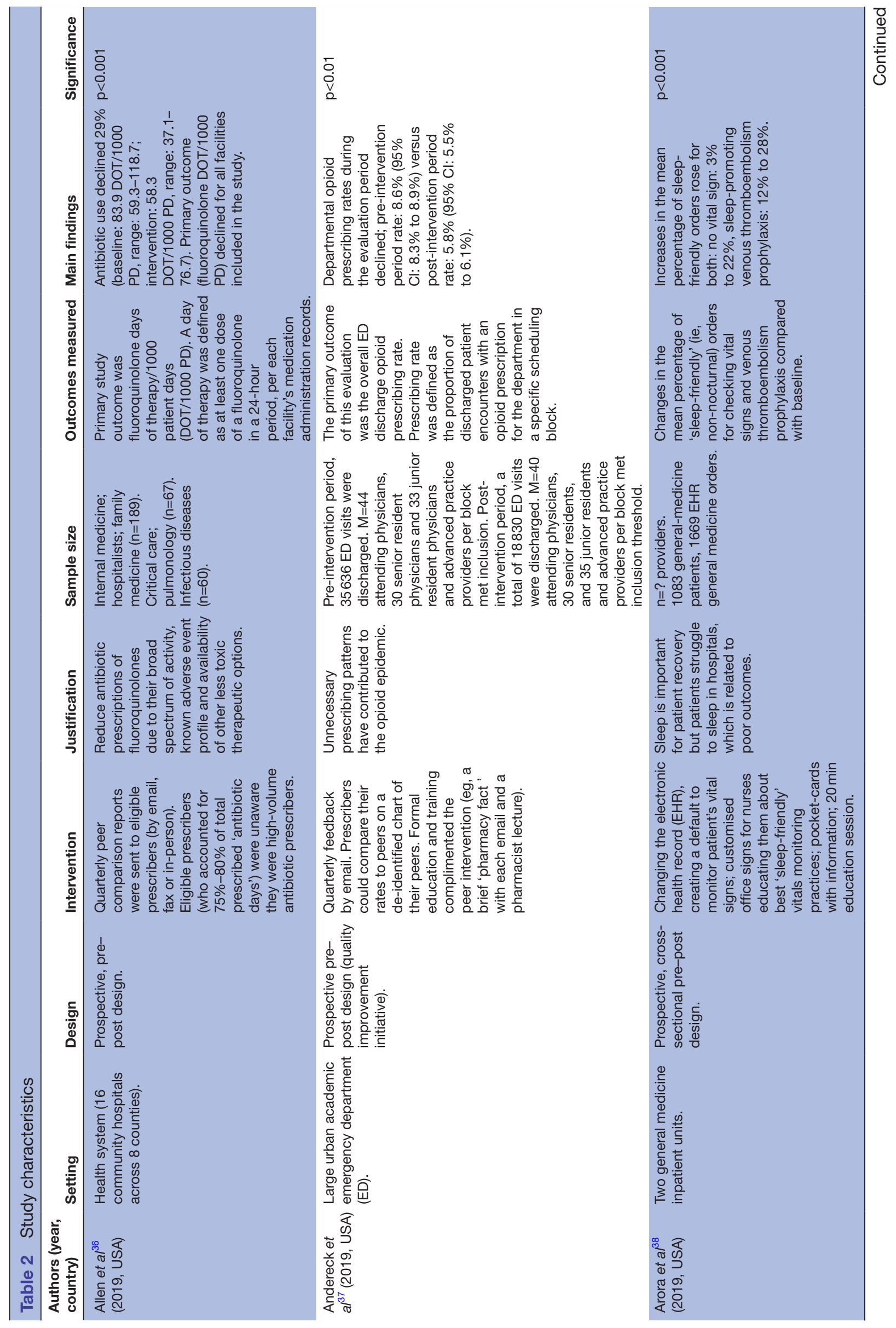




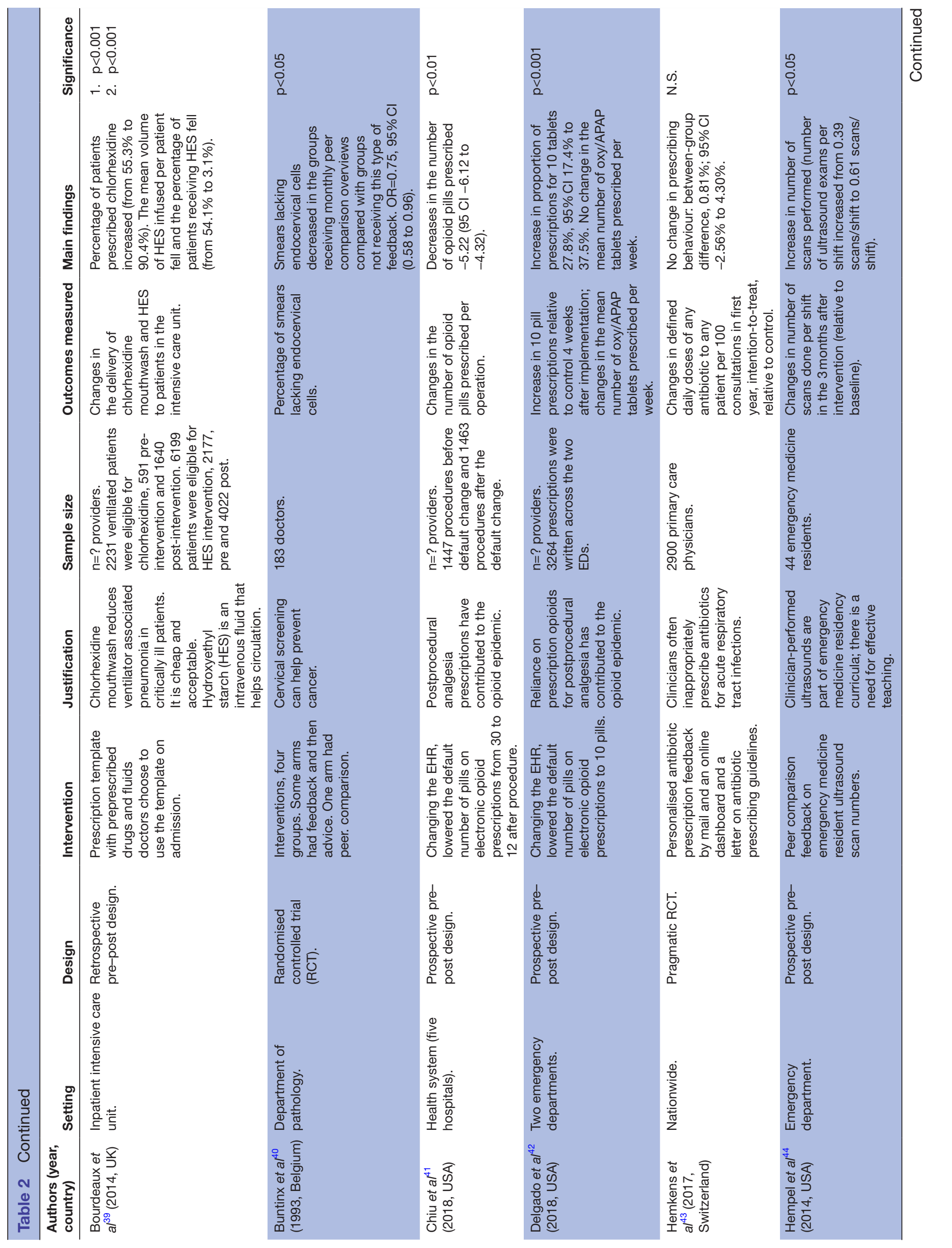




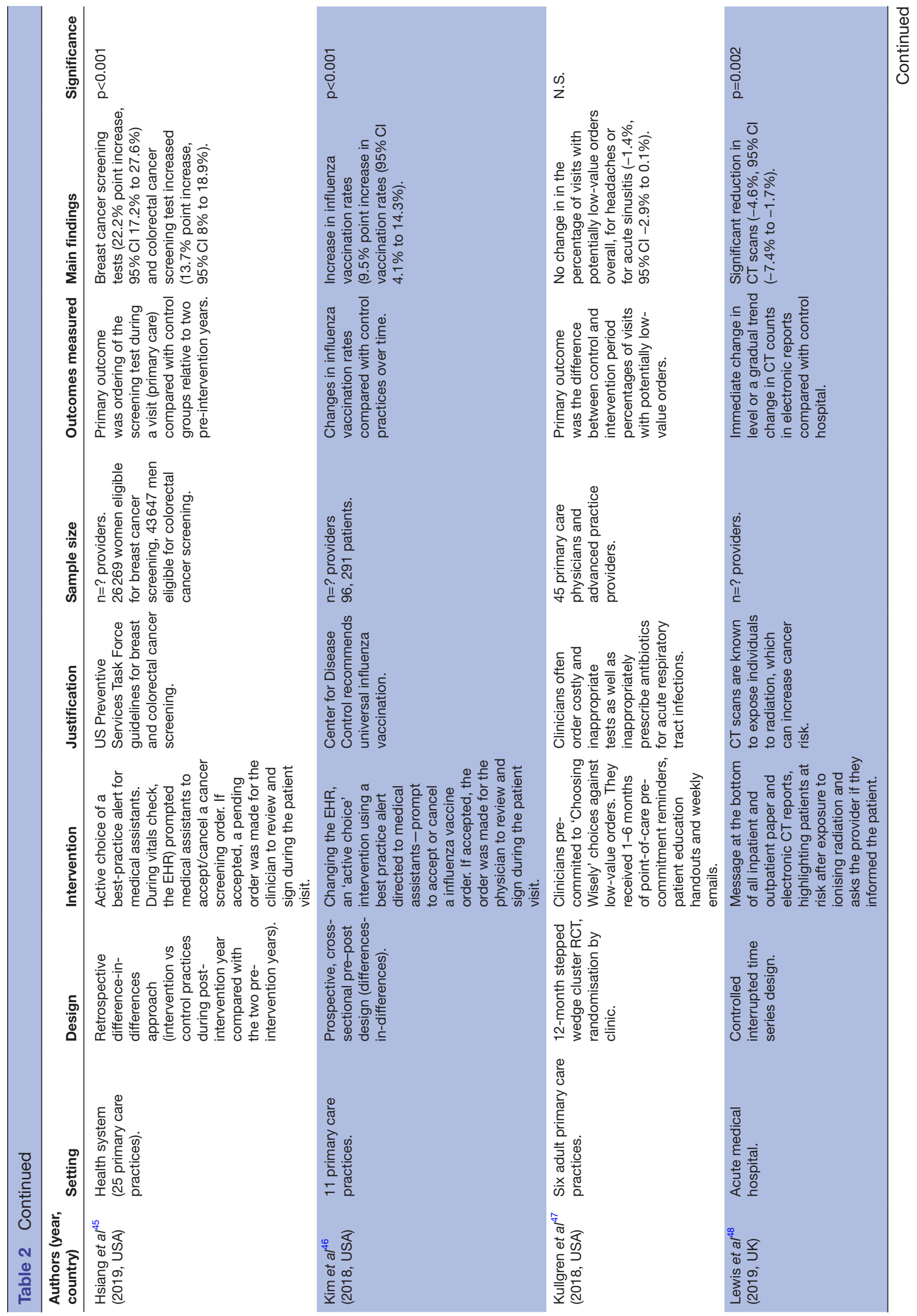

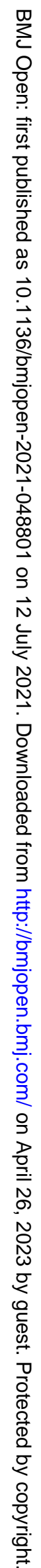




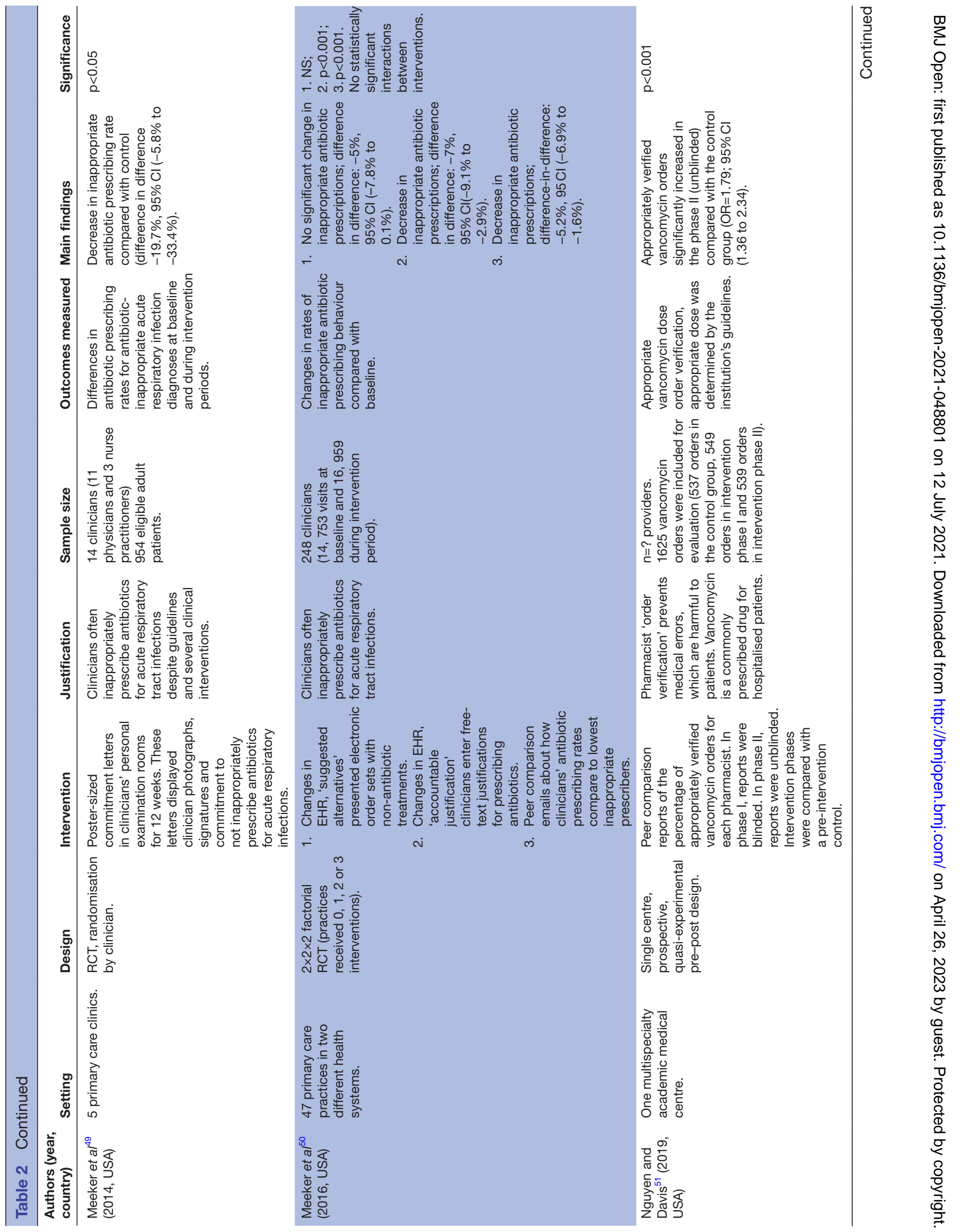




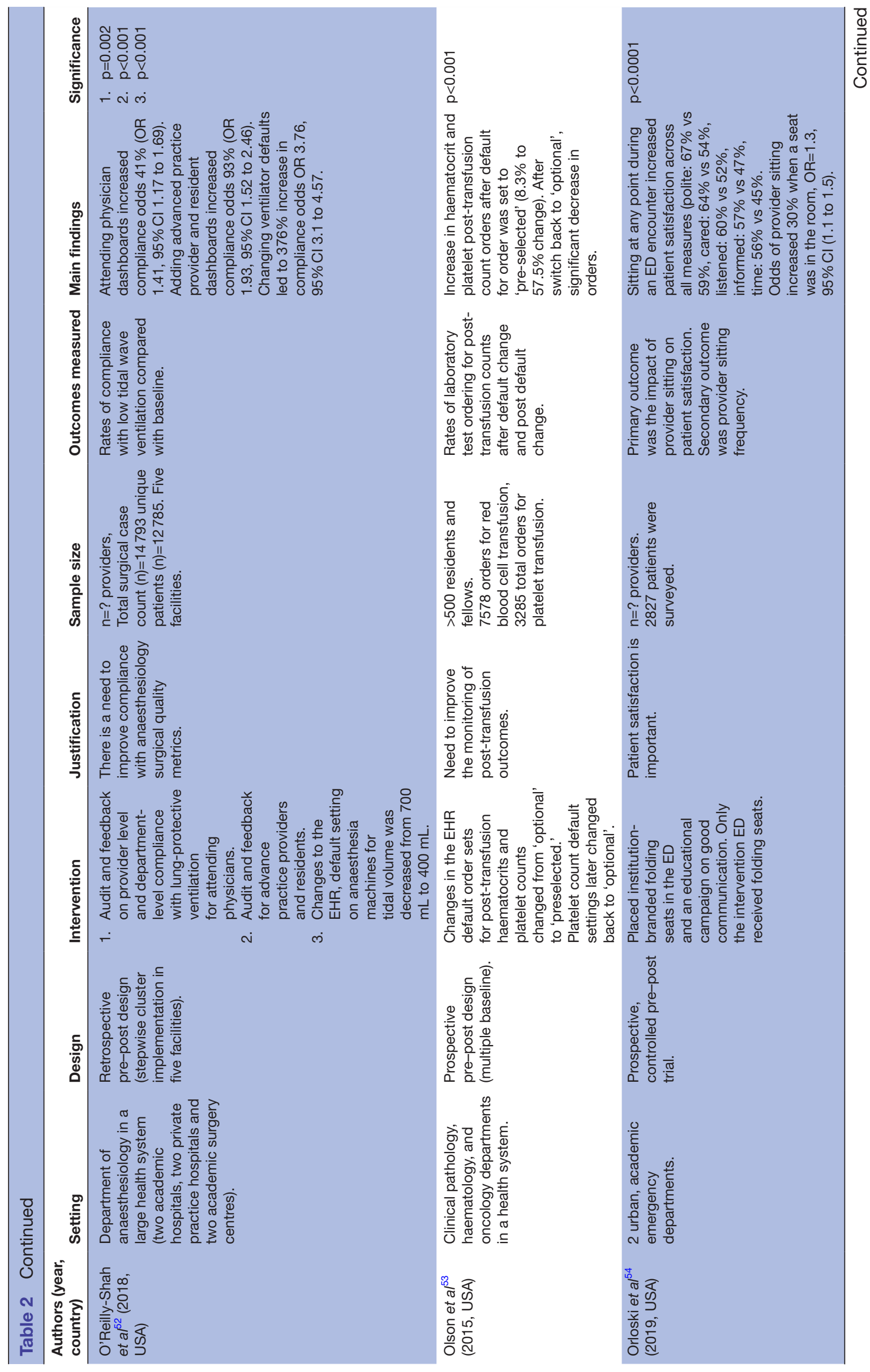




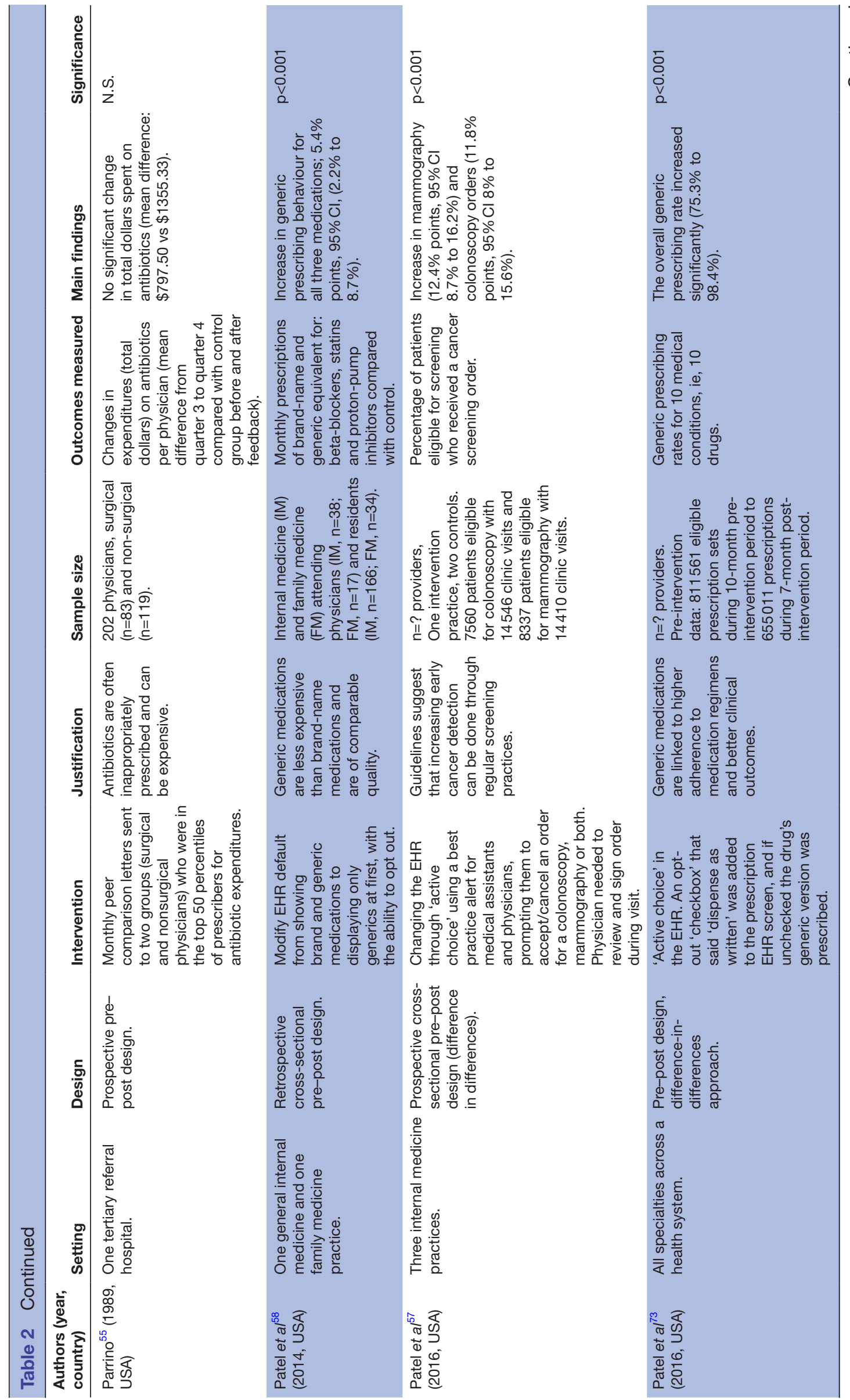




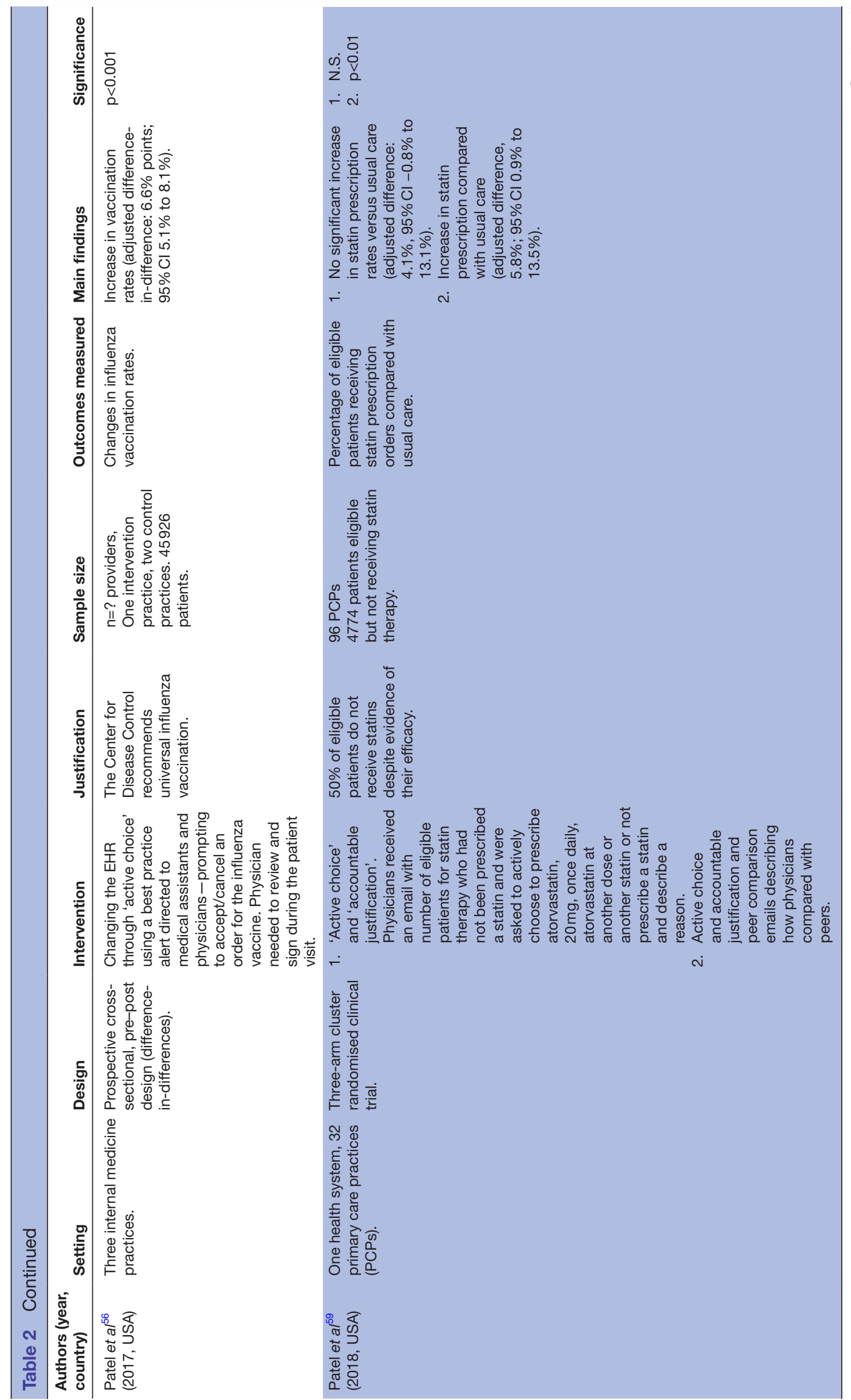

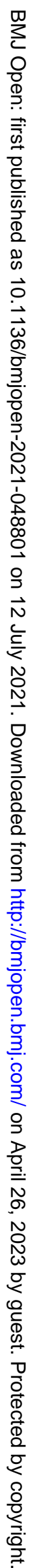




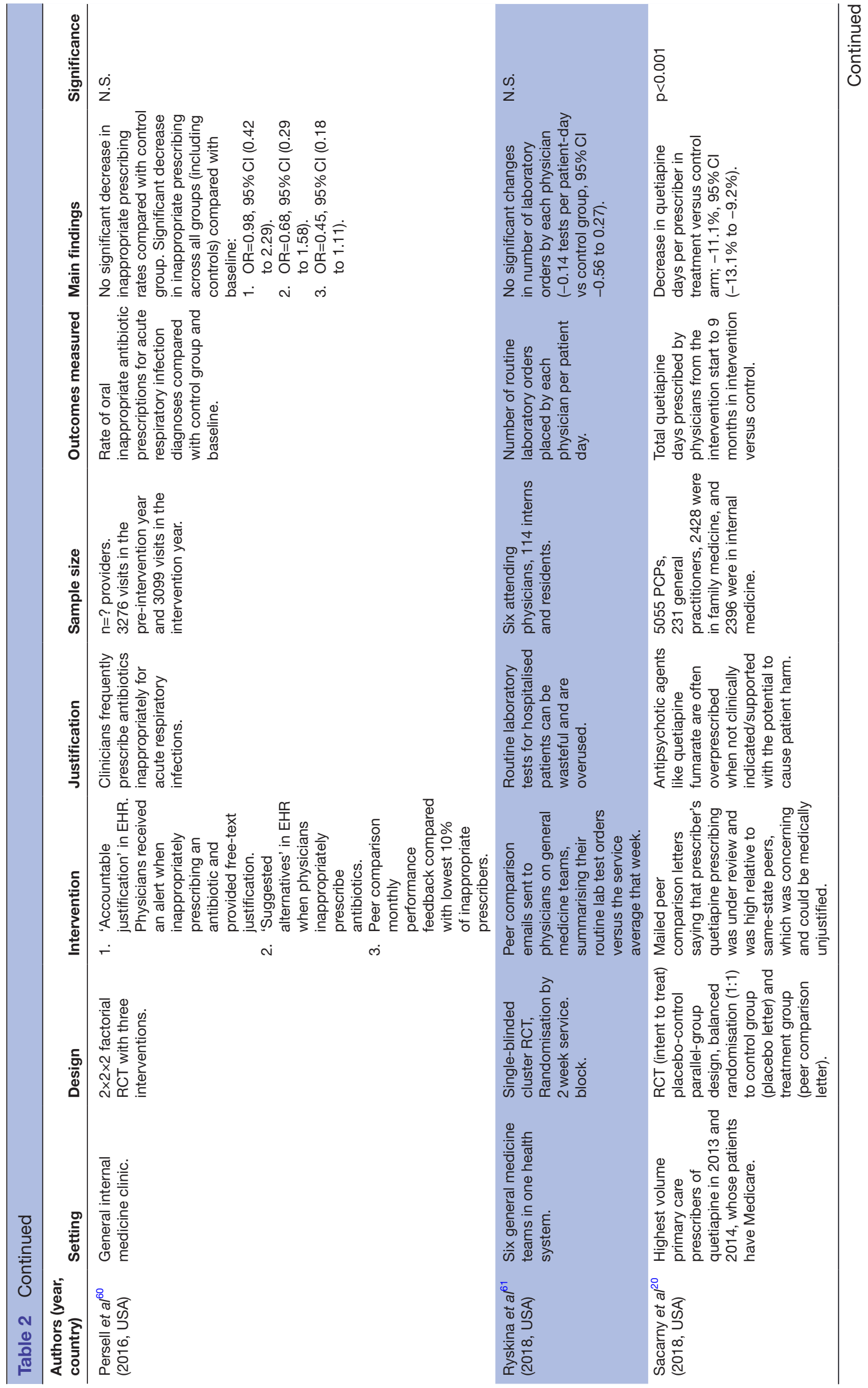




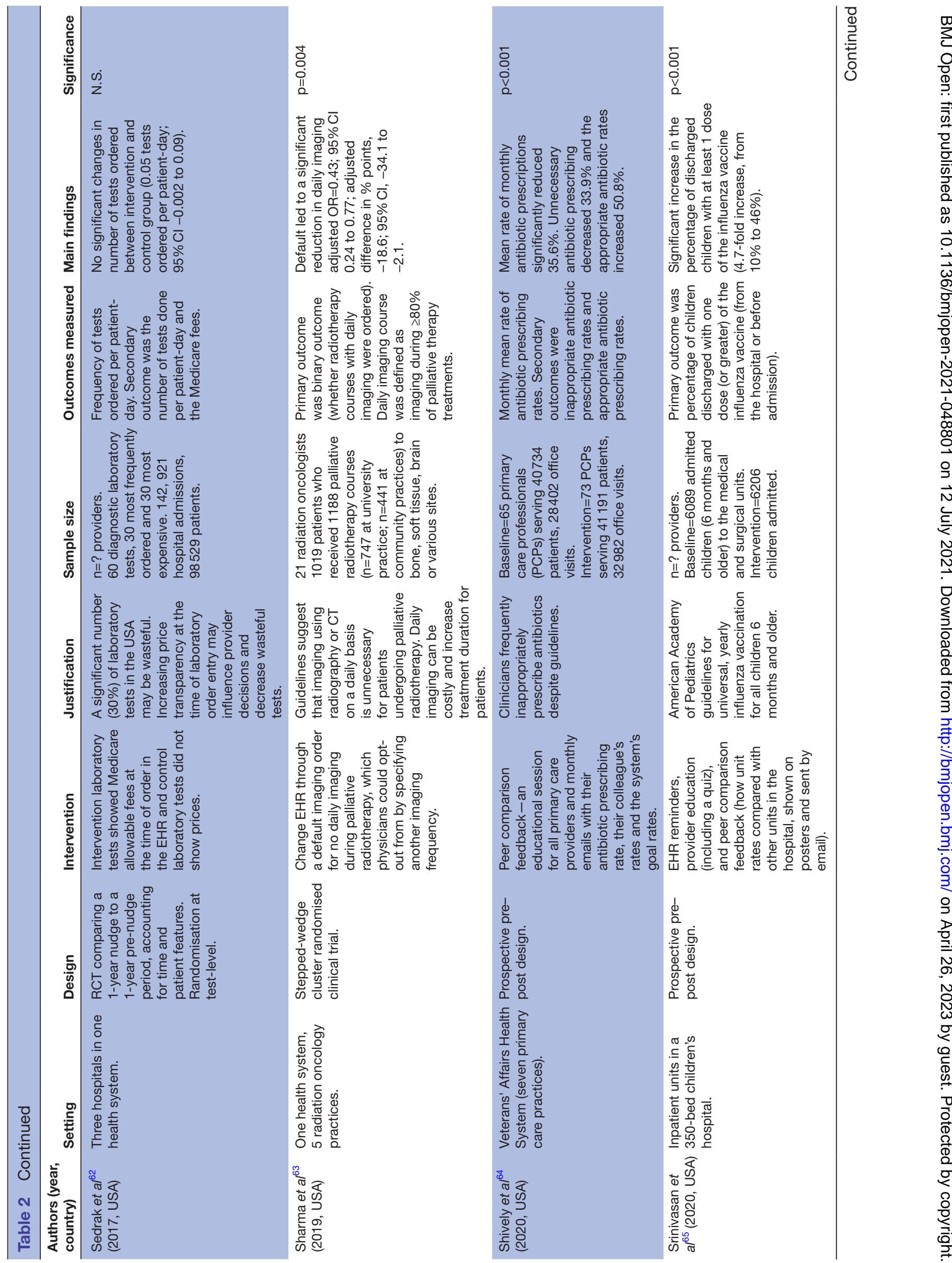




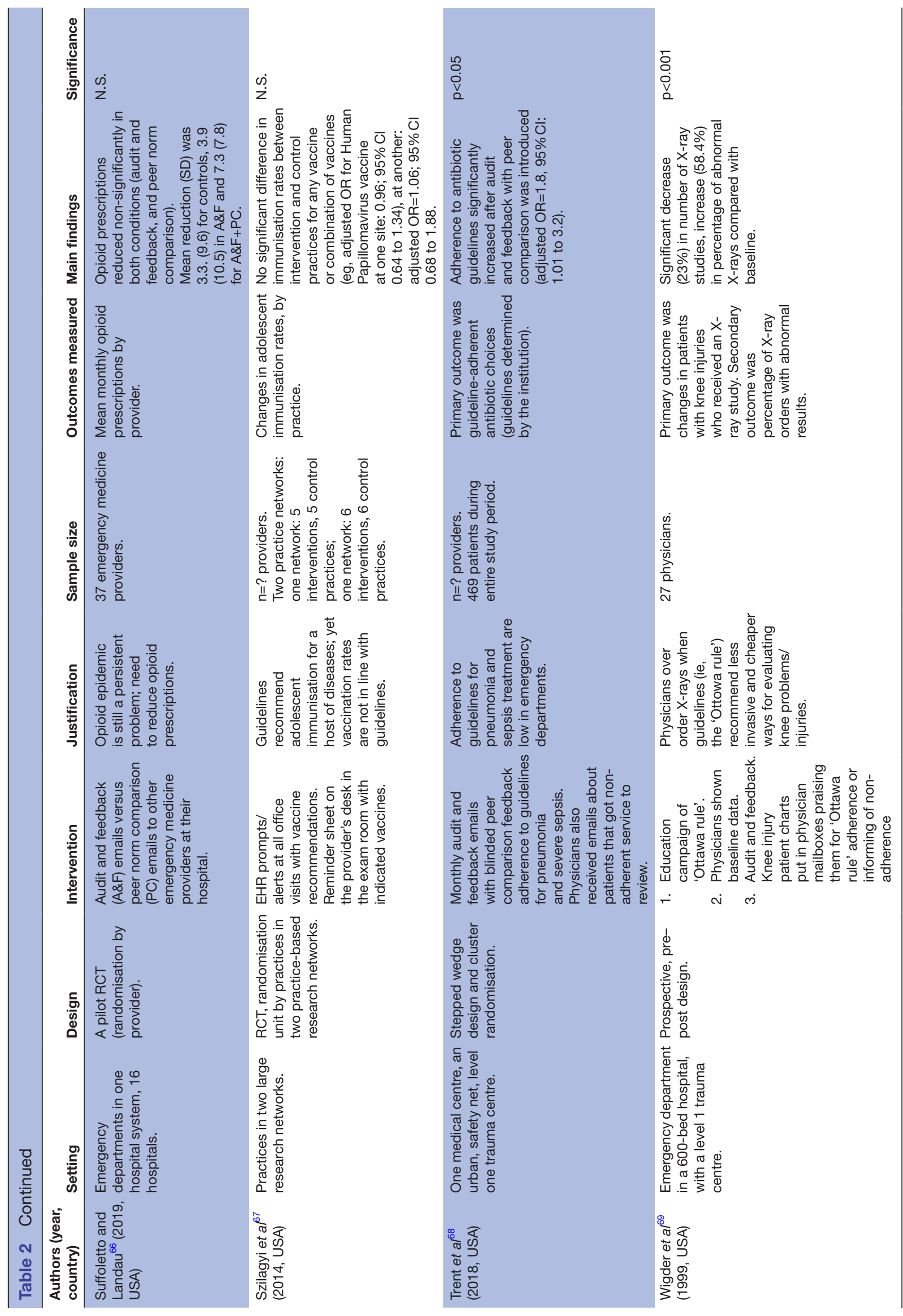




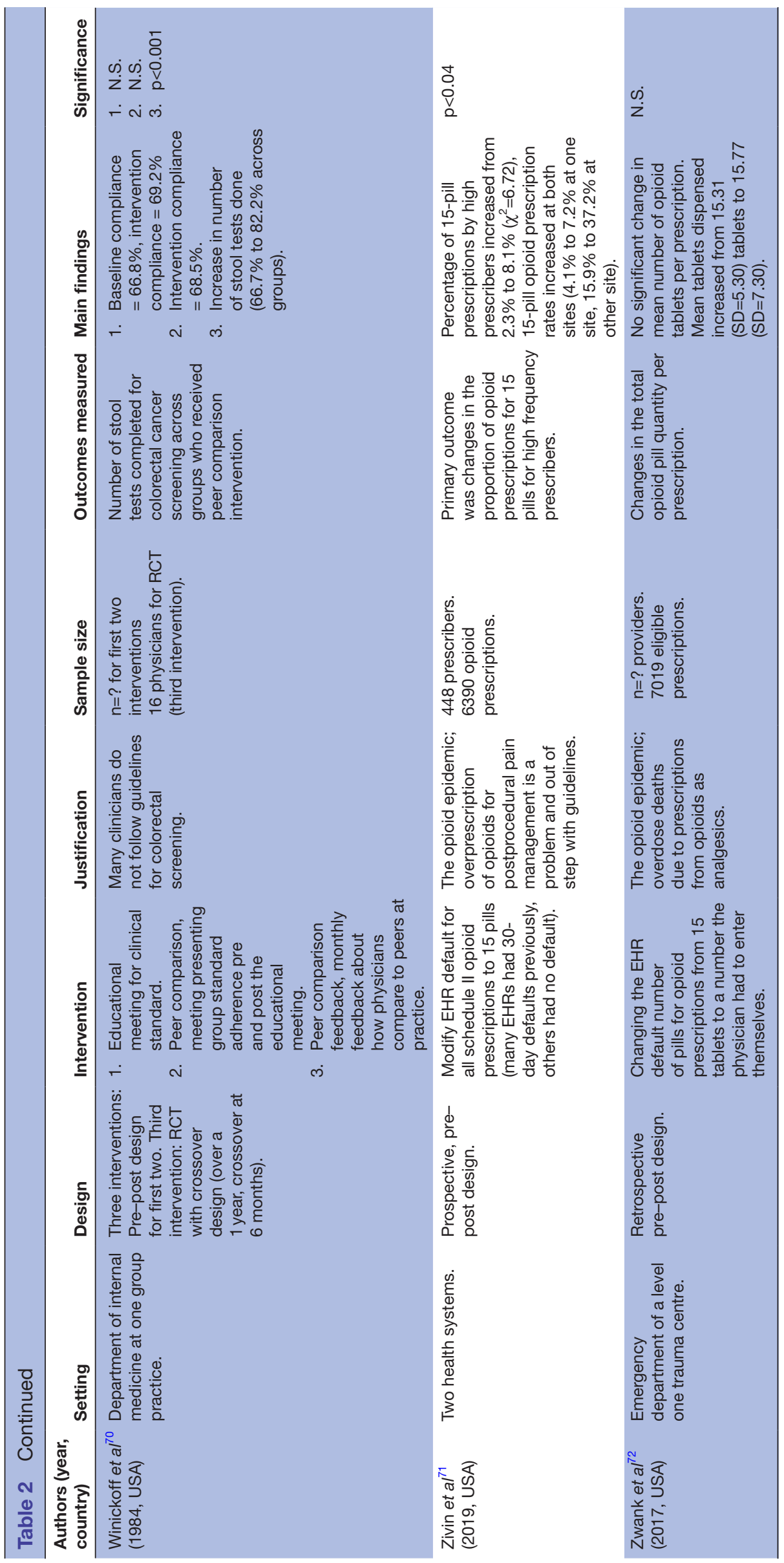


departments) and targeted a variety of clinical decisions (eg, opioid prescriptions, preventative cancer screening, checking vital signs of hospitalised patients). Nudges were directed at a variety of medical professionals (including physicians, nurses, medical assistants and providers with a license to prescribe medication). Many ( $n=20,51 \%)$ of the studies did not report the sample size of clinicians interacting with the nudges. Instead, the studies tended to report the sample size in terms of how many patients were affected by the nudge or the number of prescription or laboratory orders under study. Fourteen (36\%) studies were RCTs; 23 studies (59\%) were pre-post designs; one study (3\%) was a controlled interrupted time series design; and one study (3\%) was a quasi-experimental randomised design. In terms of cluster RCTs, four studies $(10 \%)$ were parallel cluster RCTs and three studies were stepped wedge cluster RCTs (8\%). Most studies ( $\mathrm{n}=32$, $82 \%$ ) employed a control group/comparator that consisted of usual care or no intervention. One study (3\%) used a minimal educational intervention, another study $(3 \%)$ examining peer comparison letters used a placebo letter and five studies (13\%) employed a factorial design in which multiple combined interventions were tested against individual interventions separately.

Of the 39 studies included in the review, 48 nudges were tested. Some studies contained multiple substudies, study arms or treatment groups, which were coded and analysed separately (see table 3 ). Given that some interventions $(n=5)$ were multicomponent (ie, combinations of multiple nudges) these studies were analysed separately using the nudge ladder (see table 4).

Analysing the single component nudges using the nudge ladder, 6 nudges involved guiding choice through default options (eg, changing the default opioid prescription quantity in the EHR); 9 nudges involved enabling choice (eg, electronic prompts to accept or cancel orders for influenza vaccination); 22 nudges involved framing information (eg, peer comparison letters to the clinicians in the top 50th percentile of antipsychotic prescriptions); two nudges involved prompting implementation commitments (eg, displaying clinicians' pre-commitment letters in their own examination rooms) and four nudges involved providing information (eg, an EHR reminder to clinicians when their patients were due for immunisations). Five studies involved multicomponent nudges, with four studies involving a combination of two nudges and one study involving a combination of three nudges (see table 4).

\section{Risk of bias of included studies}

Most studies were at high risk for selection bias including random sequence generation $(\mathrm{n}=25)$ and allocation concealment $(n=25)$. Attrition bias was low risk based on incomplete outcome data $(n=31)$. A large number of trials were judged as unclear for selective reporting $(n=21)$. In terms of blinding of participants, most studies were high risk $(n=25)$ and in terms of blinding outcome assessment, 25 studies were judged as having unclear risk of bias. Overall, 13 studies (33\%) were considered low risk of bias across all criteria (see table 5).

\section{Synthesis of results}

With significance defined as $(p<0.05), 33$ of the 48 nudges $(73 \%)$ significantly improved clinical decisions, suggesting that nudges are generally effective. According to the nudge ladder, all six $(100 \%)$ of the nudges that involved changing the default option to guide decisionmaking were significantly related to clinician behaviour change in the hypothesised direction. Seven of the nine $(78 \%)$ nudges that enabled choice led to significant change in clinician behaviour. Fourteen of the 22 (64\%) nudges that involved framing information changed behaviour significantly, suggesting their effectiveness. One of the two $(50 \%)$ nudges that prompted implementation commitments was significantly effective and the other was not. None of the four $(0 \%)$ nudges that provided information to clinicians resulted in statistically significant results. The five studies $(100 \%)$ that combined nudges in multicomponent interventions all led to statistically significant changes in the hypothesised direction.

Guiding choice through default options or enabling choice through an 'active opt-out' model (ie, active choice) were the most effective interventions in changing clinician behaviour. These nudges also tended to result in the largest effect sizes. Nudges that framed information-the plurality of nudges under study-tended to also change clinician behaviour. The other types of nudges were inconclusive or had more insignificant findings than significant findings. Given that it was infeasible to conduct a meta-analysis to statistically compare the nudge effects and vote-counting is subject to several methodological issues, findings should not be viewed as definitive.

\section{DISCUSSION}

\section{Summary of evidence}

This systematic review of 39 studies found that a variety of nudge interventions have been tested to improve clinical decisions. Thirty-three of the 48 (73\%) cliniciandirected nudges significantly improved clinical practice in the hypothesised direction. Nudges that changed default options or enabled choice were the most effective and nudges framing information for clinicians were also largely effective. Conversely, nudges that provided information to the clinician through reminders and prompting implementation commitments did not conclusively lead to significant changes in clinician behaviour.

One strength of the taxonomy organising this review is the ability to explicate why certain nudges are more effective and the mechanism by which they operate. Drawing on the nudge ladder, evidence suggests that less potent healthcare nudges lower on the ladder such as providing information and prompting commitments may be less effective than more potent nudges that are higher on the ladder such as changing the default options. This accords 
Table 3 Studies organised according to nudge ladder

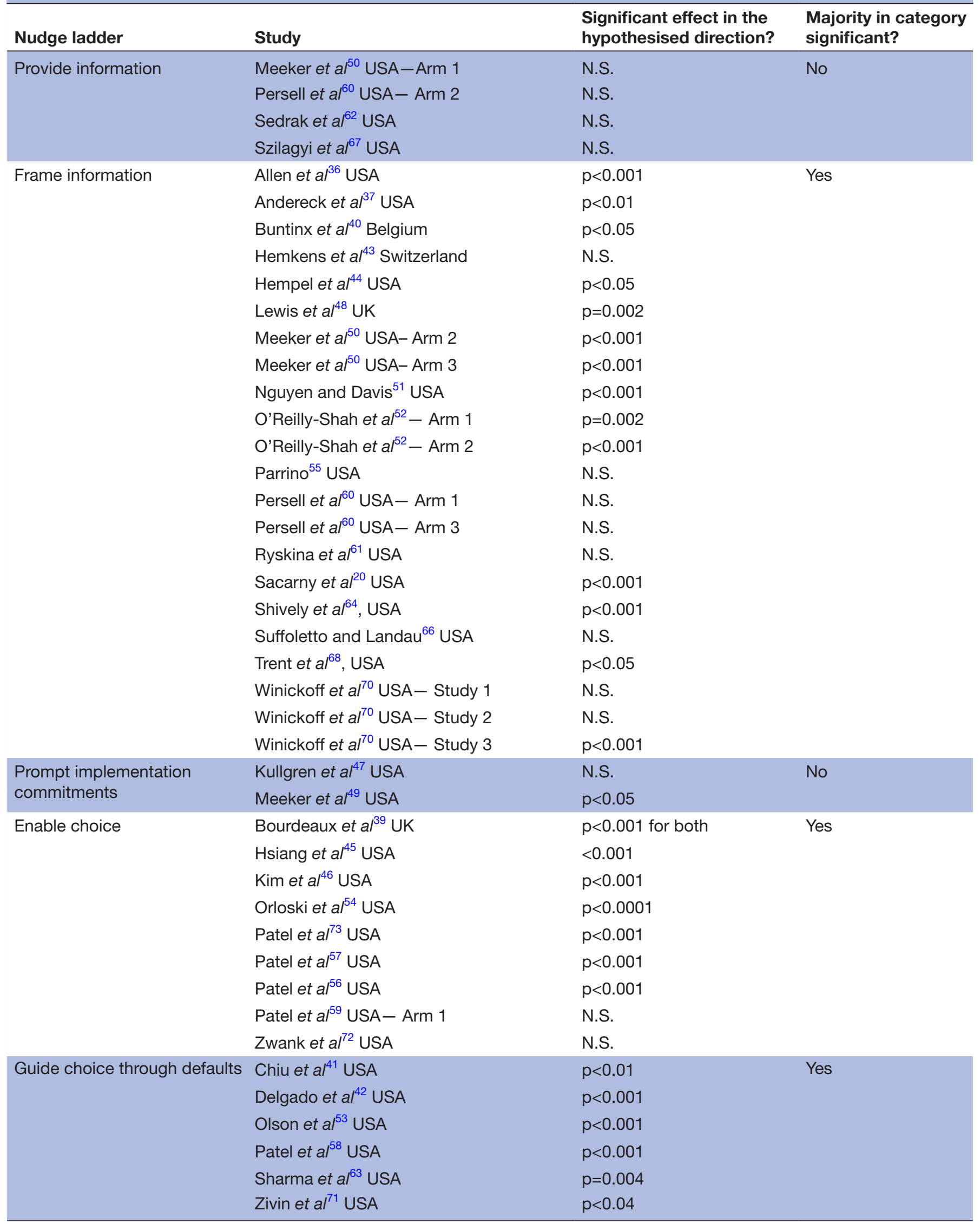

Articles that included multiple intervention treatment groups, studies or study arms are described. 
Table 4 Multicomponent intervention studies organised according to nudge ladder

\begin{tabular}{|c|c|c|}
\hline Nudge ladder & Study & $\begin{array}{l}\text { Significant effect in the } \\
\text { hypothesised direction? }\end{array}$ \\
\hline $\begin{array}{l}\text { Provide information + guide choice through } \\
\text { defaults }\end{array}$ & Arora et $\left.a\right|^{38}$ USA & $\mathrm{p}<0.001$ \\
\hline Provide information + frame information & Wigder et a/ ${ }^{69}$ USA & $\mathrm{p}<0.001$ \\
\hline Enable choice + frame information & Patel et $a l^{59}$ USA - Arm 2 & $\mathrm{p}<0.001$ \\
\hline $\begin{array}{l}\text { Provide information + frame information + enable } \\
\text { choice }\end{array}$ & Srinivasan et al ${ }^{65}$ USA & $\mathrm{p}<0.001$ \\
\hline
\end{tabular}

with nudge research in other areas outside of healthcare. ${ }^{74}$ For example, one study comparing various types of nudges that increase the salience of information $(\mathrm{eg}$, including providing reminders, leveraging social norms and framing information) with defaults found that only default nudges were effective at changing consumer proenvironmental behaviour. ${ }^{8}$ One large RCT of calorie labelling in restaurants found that posting caloric benchmarks (an informational nudge) paradoxically increased caloric intake for consumers. ${ }^{75}$

The theoretical reasons for why less potent nudges (ie, nudges at the bottom of nudge ladder) often fail are well established. People have a limited capacity to process information, so providing more data to decision-makers can be distracting or cognitively loading. ${ }^{76}$ The timing of information is also essential-information is beneficial if it is top-of-mind during the decision. ${ }^{77}$ Some of the social comparison nudges in this review provided information at opportune times, others did not. ${ }^{43}$ Additionally, information improves decisions only if existing heuristics encourage errors. Often the information individuals receive may not be new to them. Worse still, informational nudges can have negative unintended consequences. For example, alert fatigue describes when clinicians are so inundated by alerts that they become desensitised and either miss or postpone their responses to them. ${ }^{78}$ Finally, often reminders and information frames can be insufficiently descriptive in the course of action they suggest, rendering them futile. Given how much of clinicians' time is spent with the EHR, health system decision supports must be effective and not self-undermining.

More potent nudges (ie, nudges at the top of the nudge ladder) are successful because they act on several key heuristics. ${ }^{79}$ Defaults leverage inertia wherein overriding the default requires an active decision. ${ }^{80}$ When people are busy and their attention scarce, they tend to rely on the status quo. ${ }^{81}$ Moreover, people often see the default option as signaling an injunctive norm. ${ }^{82}$ They see the default choice as the recommended choice and do not want to actively override this option unless they are very confident in their private decision. It is not surprising that our study found that defaults were effective. It is also not surprising that nudges leveraging peer comparison tended to also be effective at shaping clinician behaviour-clinicians who received messages that their behaviour was abnormal compared with their peers, received a signal that helped them update their behaviour.

Overall, results align with the conclusions of one ${ }^{23}$ of the two recent systematic reviews of nudges tested in healthcare settings. ${ }^{22} 23$ Differences in findings may be explained by different search strategies. One of these systematic reviews exclusively searched RCTs included in the Cochrane Library of systematic reviews and found that priming nudges-nudges that provide cues to participants-were the most studied and most effective nudges. ${ }^{22}$ In that review, priming encompassed heterogenous interventions that span cues that elude conscious awareness, audit-and-feedback and clinician remindersto name a few-which may account for why study authors found those nudges to be the most numerous. The findings from our review conform with the results of the more traditional systematic review, conducted using a systematic search of several databases. ${ }^{23}$ The latter review, like this one, found that default and social comparison nudges were the most frequently studied and most effective nudges. However, study authors focused their review on physician behaviour, and our review is more expansive by studying all healthcare workers.

\section{Limitations}

Many of the studies in this review included at least some education (ie, a non-nudge intervention) such as a reminder of the clinical guidelines. Because many studies $(59 \%)$ were pre-post designs, they could not use these brief trainings in a control arm to evaluate the independent effect of the nudge. Therefore, we cannot decisively conclude whether nudges alone are responsible for the changes in clinician behaviour. Similarly, many of the studies $(51 \%)$ did not report the number of clinicians involved in the study (often reporting the sample in terms of how many patients or laboratory orders were affected by the nudge). Though unlikely, many of the effects could presumably be driven by a small portion of clinicians.

There was considerable variability in how researchers operationalised their primary outcome of interest. The effect of nudges may be contingent on the behaviour 
Table 5 Cochrane risk of bias assessment tool

\begin{tabular}{|c|c|c|c|c|c|c|}
\hline Authors (year, country) & $\begin{array}{l}\text { Random } \\
\text { sequence } \\
\text { generation }\end{array}$ & $\begin{array}{l}\text { Allocation } \\
\text { concealment }\end{array}$ & $\begin{array}{l}\text { Blinding } \\
\text { (participants and } \\
\text { personnel) }\end{array}$ & $\begin{array}{l}\text { Blinding } \\
\text { outcome } \\
\text { assessors }\end{array}$ & $\begin{array}{l}\text { Incomplete } \\
\text { outcome } \\
\text { data }\end{array}$ & $\begin{array}{l}\text { Selective } \\
\text { reporting }\end{array}$ \\
\hline Allen et $\mathrm{a}^{36}(2019, \mathrm{USA})$ & - & - & - & & 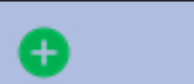 & \\
\hline Andereck et $\left.a\right|^{37}$ (2019, USA) & & $\rightarrow$ & - & ? & & \\
\hline Arora et a/ ${ }^{38}(2019$, USA) & & - & - & & & \\
\hline Bourdeaux et al ${ }^{39}$ (2014, UK) & & & - & & & \\
\hline Buntinx et al/0 (1993, Belgium) & $\oplus$ & 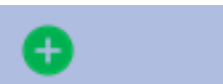 & 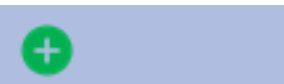 & 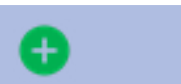 & 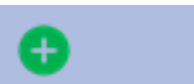 & \\
\hline Chiu et $a /^{41}(2018$, USA) & & - & - & & & $\oplus$ \\
\hline Delgado et $a^{42}(2018$, USA) & & - & - & & + & \\
\hline Hemkens et a/ ${ }^{43}$ (2017, Switzerland) & 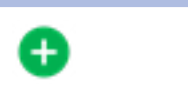 & 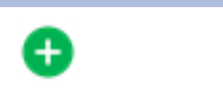 & 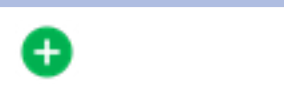 & 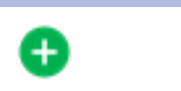 & 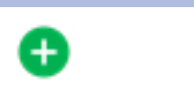 & 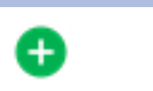 \\
\hline Hempel et al ${ }^{44}(2014$, USA) & & - & - & & & \\
\hline Hsiang et al/5 (2019, USA) & & & & & & \\
\hline Kim et $a{ }^{46}(2018$, USA) & & - & - & & + & 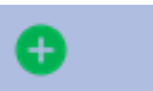 \\
\hline Kullgren et al ${ }^{47}$ (2018, USA) & 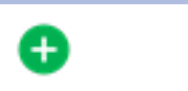 & 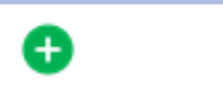 & 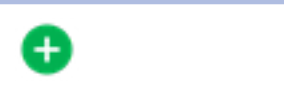 & 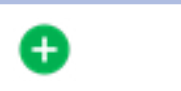 & & \\
\hline Lewis et a/8 $(2019$, UK) & & - & - & & & 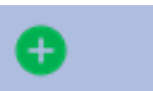 \\
\hline Meeker et al ${ }^{49}(2014$, USA) & $\oplus$ & 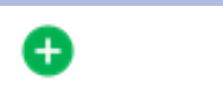 & + & 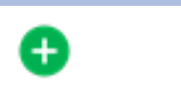 & & \\
\hline Meeker et a $\left.\right|^{50}(2016$, USA) & + & 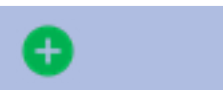 & + & 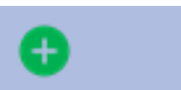 & + & $\oplus$ \\
\hline Nguyen and Davis ${ }^{51}$ (2019, USA) & & & & & & \\
\hline O'Reilly-Shah et al/52 (2018, USA) & & - & - & & + & 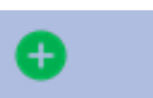 \\
\hline Olson et al ${ }^{53}(2015$, USA $)$ & & & & & & \\
\hline Orloski et a/ ${ }^{54}(2019$, USA) & & & & & & \\
\hline Parrino $^{55}$ (1989, USA) & & & & & & \\
\hline Patel et al ${ }^{58}(2014$, USA) & & & & & 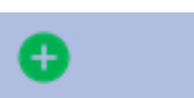 & \\
\hline Patel et al ${ }^{73}$ (2016, USA) & 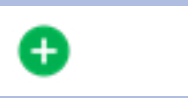 & + & 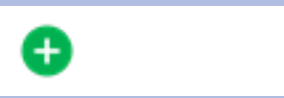 & 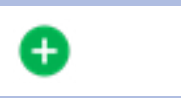 & 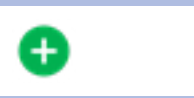 & 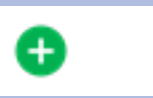 \\
\hline Patel et a ${ }^{57}$ (2016, USA) & $\oplus$ & $\oplus$ & $\oplus$ & $\oplus$ & $\oplus$ & $\oplus$ \\
\hline Patel et a/ ${ }^{56}$ (2017, USA) & $\oplus$ & $\oplus$ & $\oplus$ & $\oplus$ & $\oplus$ & $\oplus$ \\
\hline
\end{tabular}


Table 5 Continued

\begin{tabular}{|c|c|c|c|c|c|c|}
\hline Authors (year, country) & $\begin{array}{l}\text { Random } \\
\text { sequence } \\
\text { generation }\end{array}$ & $\begin{array}{l}\text { Allocation } \\
\text { concealment }\end{array}$ & $\begin{array}{l}\text { Blinding } \\
\text { (participants and } \\
\text { personnel) }\end{array}$ & $\begin{array}{l}\text { Blinding } \\
\text { outcome } \\
\text { assessors }\end{array}$ & $\begin{array}{l}\text { Incomplete } \\
\text { outcome } \\
\text { data }\end{array}$ & $\begin{array}{l}\text { Selective } \\
\text { reporting }\end{array}$ \\
\hline Patel et a/ $\left.\right|^{59}(2018$, USA) & 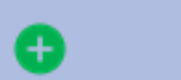 & 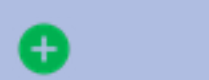 & + & 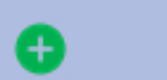 & + & \\
\hline Persell et a/ ${ }^{60}(2016$, USA) & + & + & 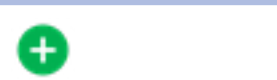 & + & 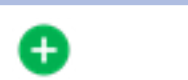 & \\
\hline Ryskina et a/ ${ }^{61}$ (2018, USA) & 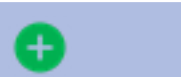 & 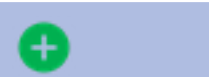 & 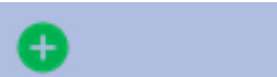 & 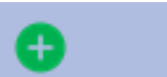 & + & \\
\hline Sacarny et al ${ }^{20}(2018$, USA) & & 9 & 9 & & + & \\
\hline Sedrak et a $/^{62}(2017$, USA) & 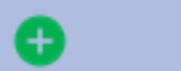 & 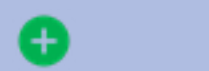 & 1 & 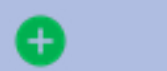 & 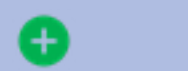 & \\
\hline Sharma et a/ ${ }^{63}$ (2019, USA) & & 0 & 0 & ? & + & \\
\hline Shively et a $/^{64}(2020$, USA) & & & & & & \\
\hline Srinivasan et a/ ${ }^{65}(2020$, USA) & & & & & & \\
\hline Suffoletto and Landau ${ }^{66}(2019$, USA) & + & $†$ & + & $\dashv$ & + & + \\
\hline Szilagyi et al ${ }^{67}$ (2014, USA) & 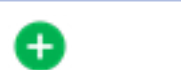 & + & & + & + & \\
\hline Trent et a/ ${ }^{68}(2018$, USA) & 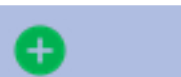 & + & + & + & + & + \\
\hline Wigder et al/99 $(1999$, USA) & & & & & & \\
\hline Winickoff et al ${ }^{70}(1984$, USA) & $\begin{array}{l}\text { First two } \\
\text { studies: } \\
\text { Third } \\
\text { study: }\end{array}$ & $\begin{array}{l}\text { First two } \\
\text { studies: } \\
\text { Third } \\
\text { study: }\end{array}$ & $\begin{array}{l}\text { First two } \\
\text { studies: } \\
\text { Third study: }\end{array}$ & & 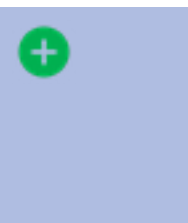 & + \\
\hline Zivin et $a l^{71}(2019$, USA) & 0 & - & - & $?$ & + & ?) \\
\hline Zwank et al/ ${ }^{72}$ (2017, USA) & - & - & - & & + & \\
\hline
\end{tabular}

indicates low risk of bias, indicates high risk of bias, and indicates unclear risk of bias. See ${ }^{34}$ for a full description of the Cochrane Risk of Bias tool.

under study. One study ${ }^{71}$ examining changes in opioid prescriptions led to a change in the number of 15-pill prescriptions (ie, the change in 'default' orders) but not in the total quantity of opioid pills prescribed, whereas other studies resulted in changes in the total number of opioid pills ordered after an EHR default change. Establishing common metrics would enable direct comparison across studies and would allow us to conclusively determine if the nudge was effective overall at improving clinical decisions.

The considerable number of included papers reporting a statistically insignificant result decreases the usual concern over publication bias, which would skew the results towards desirable and more statistically significant outcomes. The majority of studies $(n=21,54 \%)$ were at unclear risk of selective reporting of outcomes (see table 5). Moving forward, the field would benefit from reporting of all experimentation, whether its results are successful, unsuccessful, significant or insignificant. Though not a majority, a large portion of studies $(n=12$, $31 \%$ ) were conducted by the same research team in the same health system. To validate that clinician-directed nudges are effective in other settings, other researchers should conduct nudge studies. 
Though the nudge taxonomy used in the current review offered a way to classify the nudges described in the studies included, it was not developed empirically. The nudge ladder was developed based on a theoretical understanding of nudge interventions. It is important to understand whether the conceptual distinctions made between nudge types are scientifically reliable and valid.

\section{Future research}

Behavioural economics recognises that nudges are 'implicit social interactions' between the decision-maker and the choice architect. ${ }^{83}$ When faced with a nudge, people evaluate the motivations and values of the choice architect as well as how their decision will be understood by the choice architect and others. People tend to adhere to the default option when the choice architect is trusted, well-intentioned and expert. Several non-healthcare default studies backfired when consumers distrusted the choice architect or felt they were nudged to spend more money. ${ }^{84}$ Clinicians may reject nudges when they perceive health systems' preferences to conflict with their patients' interests. Research should attend to how engaged clinicians are in the implementation process and how they make inferences about the motivations and values of the choice architect when interacting with nudges using qualitative methods and surveys.

Nudges are also dependent on how decision-makers believe they will be perceived. For example, around $40 \%$ of adults seeking care for upper respiratory tract infections want antibiotics and general practitioners report that patient expectations are a major reason for prescribing antibiotics. ${ }^{85} 86$ Nudges that attempt to curtail antibiotic prescribing behaviour may shape clinicians' behaviours in unexpected ways given clinicians' desire to demonstrate to their patients that they are taking serious action. Subtle features of how nudges are implemented may also influence clinicians' perceptions of the choice architect, heighten awareness of how their own actions may be perceived and may undermine the nudge. Investigations of clinicians' choice environments and clinicians' perspectives using qualitative and survey methods are crucial to the success of nudges.

Future research should also explore how cliniciandirected nudges interact with one another in clinicians' choice environments. In our review, all multicomponent nudge studies $(n=5)$ were effective. However, it is also possible that nudges may crowd each other out when several different clinical decisions are targeted. In addition to alert fatigue, clinicians may experience nudge fatigue and begin to ignore decision support embedded in the EHR. Research should seek to understand how to develop nudges that can work synergistically with one another. Health systems and scientists can work together to understand which guidelines to prioritise and to develop decision support systems within their electronic interfaces that guide providers to make better clinical decisions.
Little work has been done on the sustainability of nudges beyond the study period, with some notable exceptions. ${ }^{87}$ Particularly for nudges that require continued intervention on the part of the choice architects (eg, peer comparison interventions), it is necessary to also understand their cost-effectiveness. Finally, understanding how nudges can be implemented across health systems is essential given that many of the studies included in this review were conducted in one health system.

\section{CONCLUSION}

This study adds to the growing literature on the study and effectiveness of nudges in healthcare contexts and can guide health systems in their choices of the types of nudges they should implement to improve clinical practice. The review describes how nudges have been employed in healthcare contexts and the evidence for their effectiveness across clinician behaviours, demonstrating potential for nudges, particularly nudges that change default settings, enable choice, or frame information for clinicians. More research is warranted to examine how nudges scale and their global effect on improving clinical decisions in complex healthcare environments.

\section{Author affiliations}

${ }^{1}$ Psychology, University of Pennsylvania, Philadelphia, Pennsylvania, USA

${ }^{2}$ Department of Family and Community Health, University of Pennsylvania School of Nursing, Philadelphia, Pennsylvania, USA

${ }^{3}$ Center for Health Incentives and Behavioral Economics (CHIBE), University of Pennsylvania, Philadelphia, Pennsylvania, USA

${ }^{4}$ Penn Implementation Science Center at the Leonard Davis Institute of Health Economics (PISCE@LDI), University of Pennsylvania, Philadelphia, Pennsylvania, USA

${ }^{5}$ College of Liberal and Professional Studies, University of Pennsylvania, Philadelphia, Pennsylvania, USA

${ }^{6}$ Department of Biostatistics, Epidemiology and Informatics, University of Pennsylvania Perelman School of Medicine, Philadelphia, Pennsylvania, USA ${ }^{7}$ Department of Psychiatry, University of Pennsylvania Perelman School of Medicine, Philadelphia, Pennsylvania, USA

${ }^{8}$ Department of Medical Ethics and Health Policy, University of Pennsylvania Perelman School of Medicine, Philadelphia, Pennsylvania, USA

${ }^{9}$ Department of Medicine, University of Pennsylvania Perelman School of Medicine, Philadelphia, Pennsylvania, USA

Acknowledgements The authors would like to thank Mitesh Patel, Anne Larrivee, Melanie Cedrone, Pamela Navrot, and Amarachi Nasa-Okolie for their assistance in the project.

Contributors BSL conceived of and designed the research study; acquired and analysed the data; interpreted the data; drafted the manuscript and substantially revised it. AMB helped design the research study; analysed the data; interpreted the data; and substantially revised the manuscript. CET analysed the data; interpreted the data; and substantially revised the manuscript. NM interpreted the data and substantially revised the manuscript. RSB helped conceive of and design the research study; interpreted the data; and substantially revised the manuscript. All authors approved the submitted version; have agreed to be accountable for the contributions; attest to the accuracy and integrity of the work, even aspects for which the authors were not personally involved.

Funding Funding for this study was provided by grants from the National Institute of Mental Health (P50 MH 113840, Beidas, Buttenheim, Mandell, MPI) and National Cancer Institute (P50 CA 244960, Beidas, Bekelman, Schnoll). BSL also receives funding support from the National Science Foundation Graduate Research Fellowship Program (DGE-1321851). 
Competing interests BSL, AMB, CET and NM declare no financial or non-financial competing interests. RSB reports royalties from 0xford University Press, has received consulting fees from the Camden Coalition of Healthcare Providers, currently consults for United Behavioral Health and sits on the scientific advisory committee for Optum Behavioral Health.

Patient consent for publication Not required.

Ethics approval Given the nature of systematic reviews, no human participant research was conducted for this original research contribution. Thus, the systematic review was not deemed subject to ethical approval and no human participants were involved in this study.

Provenance and peer review Not commissioned; externally peer reviewed.

Data availability statement Data sharing not applicable as no data sets generated for this study. Given the nature of systematic reviews, the data set generated and analysed for the current study is already available. All studies analysed for the present review are referenced for readers.

Supplemental material This content has been supplied by the author(s). It has not been vetted by BMJ Publishing Group Limited (BMJ) and may not have been peer-reviewed. Any opinions or recommendations discussed are solely those of the author(s) and are not endorsed by BMJ. BMJ disclaims all liability and responsibility arising from any reliance placed on the content. Where the content includes any translated material, BMJ does not warrant the accuracy and reliability of the translations (including but not limited to local regulations, clinical guidelines, terminology, drug names and drug dosages), and is not responsible for any error and/or omissions arising from translation and adaptation or otherwise.

Open access This is an open access article distributed in accordance with the Creative Commons Attribution Non Commercial (CC BY-NC 4.0) license, which permits others to distribute, remix, adapt, build upon this work non-commercially, and license their derivative works on different terms, provided the original work is properly cited, appropriate credit is given, any changes made indicated, and the use is non-commercial. See: http://creativecommons.org/licenses/by-nc/4.0/.

ORCID iD

Briana S Last http://orcid.org/0000-0002-5473-1357

\section{REFERENCES}

1 Simon HA. Models of bounded rationality: empirically grounded economic reason. Cambridge, MA: MIT press, 1997.

2 Gigerenzer G, Gaissmaier W. Heuristic decision making. Annu Rev Psychol 2011;62:451-82.

3 Tversky A, Kahneman D. Judgment under uncertainty: Heuristics and biases. Science 1974;185:1124-31.

4 Thaler RH, Sunstein CR. Nudge: improving decisions about health, wealth, and happiness. Revised and expanded Edition. New York, NY: Penguin Books, 2009

5 Szaszi B, Palinkas A, Palfi B, et al. A systematic scoping review of the choice architecture movement: toward understanding when and why nudges work. J Behav Decis Mak 2018;31:355-66.

6 Arno A, Thomas S. The efficacy of nudge theory strategies in influencing adult dietary behaviour: a systematic review and metaanalysis. BMC Public Health 2016;16:676.

7 Harbers MC, Beulens JWJ, Rutters F, et al. The effects of nudges on purchases, food choice, and energy intake or content of purchases in real-life food purchasing environments: a systematic review and evidence synthesis. Nutr J 2020;19:1-27.

8 Momsen K, Stoerk T. From intention to action: can nudges help consumers to choose renewable energy? Energy Policy 2014;74:376-82.

9 Blumenthal-Barby JS, Krieger H. Cognitive biases and heuristics in medical decision making: a critical review using a systematic search strategy. Med Decis Making 2015;35:539-57.

10 Croskerry P. A universal model of diagnostic reasoning. Acad Med 2009;84:1022-8.

11 Graber M. Diagnostic errors in medicine: a case of neglect. Jt Comm J Qual Patient Saf 2005;31:106-13.

12 Almashat S, Ayotte B, Edelstein B, et al. Framing effect debiasing in medical decision making. Patient Educ Couns 2008;71:102-7.

13 Saposnik G, Redelmeier D, Ruff CC, et al. Cognitive biases associated with medical decisions: a systematic review. BMC Med Inform Decis Mak 2016;16:138.

14 Mendel R, Traut-Mattausch E, Jonas E, et al. Confirmation bias: why psychiatrists stick to wrong preliminary diagnoses. Psychol Med 2011;41:2651-9.
15 Redelmeier DA, Shafir E. Medical decision making in situations that offer multiple alternatives. JAMA 1995;273:302-5.

16 Patel MS, Volpp KG, Asch DA. Nudge units to improve the delivery of health care. N Engl J Med 2018;378:214-6.

17 Chaiyachati KH, Shea JA, Asch DA, et al. Assessment of inpatient time allocation among first-year internal medicine residents using time-motion observations. JAMA Intern Med 2019;179:760.

18 Hsiao C-J, Hing E. Use and characteristics of electronic health record systems among office-based physician practices: United States, 2001-2012. NCHS Data Brief 2014;143:1-8.

19 Henry J, Pylypchuk Y, Searcy TONC Data Brief, no.35. Adoption of electronic health record systems among U.S. Non-Federal acute care hospitals: 2008-2015. Washington DC Office of the National Coordinator for Health Information Technology; 2016.

20 Sacarny A, Barnett ML, Le J, et al. Effect of peer comparison letters for high-volume primary care prescribers of quetiapine in older and disabled adults: a randomized clinical trial. JAMA Psychiatry 2018;75:1003-11.

21 Lewis CC, Klasnja P, Powell BJ, et al. From classification to causality: advancing understanding of mechanisms of change in implementation science. Front Public Health 2018;6:136.

22 Yoong SL, Hall A, Stacey F, et al. Nudge strategies to improve healthcare providers' implementation of evidence-based guidelines, policies and practices: a systematic review of trials included within Cochrane systematic reviews. Implementation Science 2020;15:1-30.

23 Wang SY, Groene O. The effectiveness of behavioral economicsinformed interventions on physician behavioral change: a systematic literature review. PLoS One 2020;15:e0234149.

24 Nuffield Council on Bioethics. Public health: ethical issues [Internet]. London, UK: Nuffield Council on Bioethics, 2007: 1-225. https:// www.nuffieldbioethics.org/assets/pdfs/Public-health-ethical-issues. pdf

25 Patel MS. Nudges for influenza vaccination. Nat Hum Behav 2018;2:720-1.

26 Hillier-Brown FC, Summerbell CD, Moore HJ, et al. The impact of interventions to promote healthier ready-to-eat meals (to eat in, to take away or to be delivered) sold by specific food outlets open to the general public: a systematic review. Obes Rev 2017;18:227-46.

27 Münscher R, Vetter M, Scheuerle T. A review and taxonomy of choice architecture techniques. J Behav Decis Mak 2016;29:511-24.

28 Sunstein CR. Nudges vs. shoves. Harv L Rev F 2013;127:210

29 Flodgren G, Eccles MP, Shepperd S, et al. An overview of reviews evaluating the effectiveness of financial incentives in changing healthcare professional behaviours and patient outcomes. Cochrane Database Syst Rev 2011:CD009255.

30 Sackett DL, Rosenberg WMC, Gray JAM, et al. Evidence based medicine: what it is and what it isn't. BMJ 1996;312:71-2.

31 Biernacki P, Waldorf D. Snowball sampling: problems and techniques of chain referral sampling. Sociol Methods Res 1981;10:141-63.

32 Higgins JPT, Green S. Cochrane handbook for systematic reviews of interventions. 1 edn. Chichester (UK): John Wiley \& Sons, 2008.

33 Davis DA, Mazmanian PE, Fordis M, et al. Accuracy of physician self-assessment compared with observed measures of competence: a systematic review. JAMA 2006;296:1094-102.

34 Higgins JPT, Altman DG, Gøtzsche PC, et al. The Cochrane collaboration's tool for assessing risk of bias in randomised trials. BMJ 2011;343:d5928.

35 Nugent WR. The (non)comparability of the correlation effect size across different measurement procedures: a challenge to metaanalysis as a tool for identifying "evidence based practices". J Evid Based Soc Work 2011;8:253-74.

36 Allen JM, Dunn R, Bush J. Effect of prescriber peer comparison reports on fluoroquinolone use across a 16-facility community hospital system. J Am Coll Clin Pharm 2019;2:502-8.

37 Andereck JW, Reuter QR, Allen KC, et al. A quality improvement initiative featuring Peer-Comparison prescribing feedback reduces emergency department opioid prescribing. Jt Comm J Qual Patient Saf 2019:45:669-79.

38 Arora VM, Machado N, Anderson SL, et al. Effectiveness of SIESTA on objective and subjective metrics of nighttime Hospital sleep disruptors. J Hosp Med 2019;14:38-41.

39 Bourdeaux CP, Davies KJ, Thomas MJC, et al. Using 'nudge' principles for order set design: a before and after evaluation of an electronic prescribing template in critical care. BMJ Qual Saf 2014;23:382-8

40 Buntinx F, Knottnerus JA, Essed GG, et al. Long-term effect of feedback and peer comparison on the sampling quality of cervical smears--a randomized controlled trial. Eur J Cancer Prev 1995;4:153-8. 
41 Chiu AS, Jean RA, Hoag JR, et al. Association of lowering default pill counts in electronic medical record systems with postoperative opioid prescribing. JAMA Surg 2018;153:1012-9.

42 Delgado MK, Shofer FS, Patel MS, et al. Association between electronic medical record implementation of default opioid prescription quantities and prescribing behavior in two emergency departments. J Gen Intern Med 2018;33:409-11.

43 Hemkens LG, Saccilotto R, Reyes SL, et al. Personalized prescription feedback using routinely collected data to reduce antibiotic use in primary care: a randomized clinical trial. JAMA Intern Med 2017; 177:176-83.

44 Hempel D, Pivetta E, Kimberly HH. Personalized peer-comparison feedback and its effect on emergency medicine resident ultrasound scan numbers. Crit Ultrasound J 2014;6:1.

45 Hsiang EY, Mehta SJ, Small DS, et al. Association of an active choice intervention in the electronic health record directed to medical assistants with clinician ordering and patient completion of breast and colorectal cancer screening tests. JAMA Netw Open 2019;2:e1915619.

$46 \mathrm{Kim} \mathrm{RH}$, Day SC, Small DS, et al. Variations in influenza vaccination by clinic appointment time and an active choice intervention in the electronic health record to increase influenza vaccination. JAMA Netw Open 2018;1:e181770.

47 Kullgren JT, Krupka E, Schachter A, et al. Precommitting to choose wisely about low-value services: a stepped wedge cluster randomised trial. BMJ Qual Saf 2018;27:355-64.

48 Lewis S, Young B, Thurley P, et al. Evaluation of a nudge intervention providing simple feedback to clinicians of the consequence of radiation exposure on demand for computed tomography: a controlled study. Clin Med 2019;19:290-3.

49 Meeker D, Knight TK, Friedberg MW, et al. Nudging guidelineconcordant antibiotic prescribing: a randomized clinical trial. JAMA Intern Med 2014;174:425-31.

50 Meeker D, Linder JA, Fox CR, et al. Effect of behavioral interventions on inappropriate antibiotic prescribing among primary care practices: a randomized clinical trial. JAMA 2016;315:562-70.

51 Nguyen CT, Davis KA. Evaluating the impact of peer comparison on vancomycin dose order verification among pharmacists. J Am Coll Clin Pharm 2019;2:137-42.

52 O'Reilly-Shah VN, Easton GS, Jabaley CS, et al. Variable effectiveness of stepwise implementation of nudge-type interventions to improve provider compliance with intraoperative low tidal volume ventilation. BMJ Qual Saf 2018;27:1008-18.

53 Olson J, Hollenbeak C, Donaldson K, et al. Default settings of computerized physician order entry system order sets drive ordering habits. J Pathol Inform 2015;6:16.

54 Orloski CJ, Tabakin ER, Shofer FS, et al. Grab a seat! Nudging providers to sit improves the patient experience in the emergency department. J Patient Exp 2019;6:110-6.

55 Parrino TA. The nonvalue of retrospective peer comparison feedback in containing Hospital antibiotic costs. Am J Med 1989;86:442-8.

56 Patel MS, Volpp KG, Small DS, et al. Using active choice within the electronic health record to increase influenza vaccination rates. $J$ Gen Intern Med 2017;32:790-5.

57 Patel MS, Volpp KG, Small DS, et al. Using active choice within the electronic health record to increase physician ordering and patient completion of high-value cancer screening tests. Healtho 2016:4:340-5

58 Patel MS, Day S, Small DS, et al. Using default options within the electronic health record to increase the prescribing of genericequivalent medications: a quasi-experimental study. Ann Intern Med 2014;161:S44-52.

59 Patel MS, Kurtzman GW, Kannan S, et al. Effect of an automated patient Dashboard using active choice and peer comparison performance feedback to physicians on statin prescribing: the prescribe cluster randomized clinical trial. JAMA Netw Open 2018;1:e180818.

60 Persell SD, Doctor JN, Friedberg MW, et al. Behavioral interventions to reduce inappropriate antibiotic prescribing: a randomized pilot trial. BMC Infect Dis 2016;16:373.

61 Ryskina K, Jessica Dine C, Gitelman Y, et al. Effect of social comparison feedback on laboratory test ordering for hospitalized patients: a randomized controlled trial. $J$ Gen Intern Med 2018;33:1639-45.

62 Sedrak MS, Myers JS, Small DS, et al. Effect of a price transparency intervention in the electronic health record on clinician ordering of inpatient laboratory tests: the price randomized clinical trial. JAMA Intern Med 2017;177:939-45.
63 Sharma S, Guttmann D, Small DS, et al. Effect of introducing a default order in the electronic medical record on unnecessary daily imaging during palliative radiotherapy for adults with cancer: a Stepped-Wedge cluster randomized clinical trial. JAMA Oncol 2019;5:1220-2.

64 Shively NR, Buehrle DJ, Wagener MM. Improved antibiotic prescribing within a Veterans Affairs primary care system through a multifaceted intervention centered on peer comparison of overall antibiotic prescribing rates. Antimicrob Agents Chemother 2020;64:e00928-19.

65 Srinivasan M, Huntman J, Nelson M, et al. Use of peer comparison, provider education, and electronic medical record triggers to increase influenza vaccination rates in hospitalized children. Hosp Pediatr 2020;10:76-83.

66 Suffoletto B, Landau A. Nudging emergency care providers to reduce opioid prescribing using peer norm comparison feedback: a pilot randomized trial. Pain Med 2020;21:1393-9.

67 Szilagyi PG, Serwint JR, Humiston SG, et al. Effect of provider prompts on adolescent immunization rates: a randomized trial. Acad Pediatr 2015;15:149-57.

68 Trent SA, Havranek EP, Ginde AA, et al. Effect of audit and feedback on physician adherence to clinical practice guidelines for pneumonia and sepsis. Am J Med Qual 2019;34:217-25.

69 Wigder HN, Cohan Ballis SF, Lazar L, et al. Successful implementation of a guideline by peer comparisons, education, and positive physician feedback. J Emerg Med 1999;17:807-10.

70 Winickoff RN, Coltin KL, Morgan MM, et al. Improving physician performance through peer comparison feedback. Med Care 1984;22:527-34.

71 Zivin K, White JO, Chao S, et al. Implementing electronic health record default settings to reduce opioid Overprescribing: a pilot study. Pain Med 2019;20:103-12.

72 Zwank MD, Kennedy SM, Stuck LH, et al. Removing default dispense quantity from opioid prescriptions in the electronic medical record. Am J Emerg Med 2017;35:1567-9.

73 Patel MS, Day SC, Halpern SD, et al. Generic medication prescription rates after health system-wide redesign of default options within the electronic health record. JAMA Intern Med 2016;176:847-8.

74 Sunstein CR. Nudges that fail. Behav Public Policy 2017;1:4-25.

75 Downs JS, Wisdom J, Wansink B, et al. Supplementing menu labeling with calorie recommendations to test for facilitation effects. Am J Public Health 2013;103:1604-9.

76 Marois R, Ivanoff $\mathrm{J}$. Capacity limits of information processing in the brain. Trends Cogn Sci 2005;9:296-305.

77 Karlan D, McConnell M, Mullainathan S, et al. Getting to the top of mind: how reminders increase saving. Manage Sci 2016:62:3393-411.

78 Sendelbach S, Funk M. Alarm fatigue: a patient safety concern. AACN Adv Crit Care 2013;24:378-86.

79 Jachimowicz JONM, Duncan S, Weber EU, et al. When and why defaults influence decisions: a meta-analysis of default effects. Behav Public Policy 2019;3:159-86.

80 Madrian BC, Shea DF. The power of suggestion: inertia in 401(k) participation and savings behavior. Q J Econ 2001;116:1149-87.

81 Kahneman D, Knetsch JL, Thaler RH. Anomalies: the endowment effect, loss aversion, and status quo bias. Journal of Economic Perspectives 1991;5:193-206.

82 Everett JAC, Caviola L, Kahane G, et al. Doing good by doing nothing? the role of social norms in explaining default effects in altruistic contexts. Eur J Soc Psychol 2015;45:230-41.

83 Krijnen JMT, Tannenbaum D, Fox CR. Choice architecture 2.0: behavioral policy as an implicit social interaction. Behavioral Science \& Policy 2017;3:i-18.

84 Brown CL, Krishna A. The skeptical shopper: a metacognitive account for the effects of default options on choice. J Consum Res 2004;31:529-39.

85 Fletcher-Lartey S, Yee M, Gaarslev C, et al. Why do general practitioners prescribe antibiotics for upper respiratory tract infections to meet patient expectations: a mixed methods study. BMJ Open 2016;6:e012244.

86 Linder JA, Singer DE. Desire for antibiotics and antibiotic prescribing for adults with upper respiratory tract infections. J Gen Intern Med 2003;18:795-801.

87 Olshan D, Rareshide CAL, Patel MS. Longer-Term durability of using default options in the electronic health record to increase generic prescribing rates. J Gen Intern Med 2019;34:349-50. 